\title{
lodobutane Deep Bed Adsorption Test Report
}

\section{Nuclear Technology \\ Research and Development}

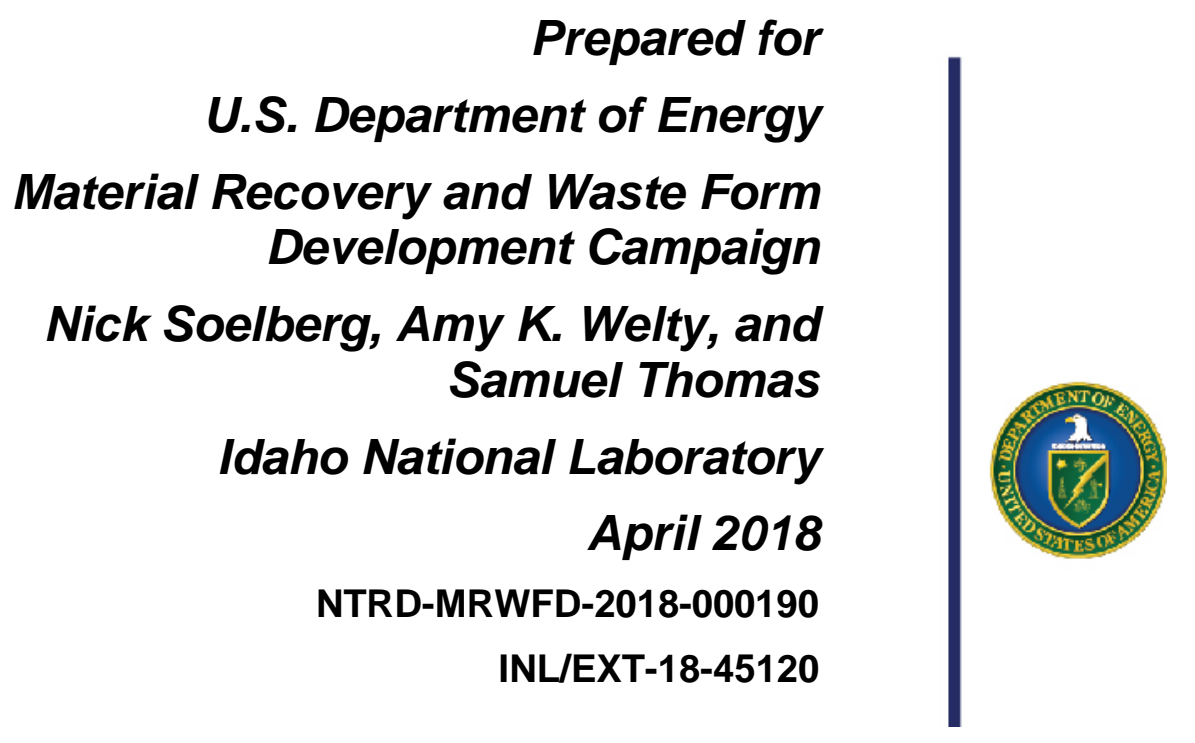




\section{DISCLAIMER}

This information was prepared as an account of work sponsored by an agency of the U.S. Government. Neither the U.S. Government nor any agency thereof, nor any of their employees, makes any warranty,

expressed or implied, or assumes any legal liability or responsibility for the accuracy, completeness, or usefulness, of any information, apparatus, product, or process disclosed, or represents that its use would not infringe privately owned rights. References herein to any specific commercial product, process, or service by trade name, trade mark, manufacturer, or otherwise, does not necessarily constitute or imply its endorsement, recommendation, or favoring by the U.S. Government or any agency thereof. The views and opinions of authors expressed herein do not necessarily state or reflect those of the U.S. Government or any agency thereof. 


\section{ACKNOWLEDGEMENTS}

The authors acknowledge others who helped guide or perform iodobutane adsorption testing this year. Jack Law of the Idaho National Laboratory (INL) and Bob Jubin of the Oak Ridge National Laboratory provided programmatic and technical direction. Cathy Rae in the INL Chemistry and Radiation Measurement Department performed gas chromatography with mass spectrometry analyses. Sample analyses were performed by Duane Ball in the INL Chemistry and Radiation Measurement Department; Arnie Erickson in the INL Materials Science and Engineering Department; and Byron Forsmann in the INL Center for Advanced Engineering Studies. 
This page blank 


\section{SUMMARY}

The Department of Energy (DOE) Nuclear Technology Research and Development (NTRD) Program Material Recovery and Waste Form Development (MRWFD) Campaign Off-gas Sigma Team has supported research and development on iodine control and iodine waste forms for the past several years. As a part of this on-going research, two deep-bed iodobutane adsorption tests have been performed with higher $\mathrm{NO}_{\mathrm{x}}$ levels. High $(>1,000)$ iodine decontamination factors (DFs, the ratios of the inlet iodine concentrations divided by the outlet iodine concentrations, when the gas flowrate is constant) were achieved with both the silver aerogel and silver zeolite sorbents.

The iodine adsorption mass transfer zone (the depth of the sorbent bed in which adsorption is occurring at any specific time) for these tests was estimated at 4 inches for both sorbents under the test conditions. Silver utilization for silver aerogel sorbent reached $41 \%$ (up to 12 g adsorbed iodine per 100 g silver aerogel sorbent), while silver utilization reached 43\% (up to $6.8 \mathrm{~g}$ adsorbed iodine per $100 \mathrm{~g}$ silver zeolite sorbent). These values are generally consistent with results for prior methyl iodide adsorption tests. The results also indicate that, during iodine adsorption process, the organic iodide molecule decomposes so that the iodine can be adsorbed. Even when sorbent breakthrough is reached, the organic iodide molecule continues to decompose; and the unadsorbed iodine that passes through bed is no longer in the form of the original organic iodide; but in the form of iodine compounds that are soluble in $\mathrm{NaOH}$ solutions, such as $\mathrm{HI}$ or $\mathrm{I}_{2}$.

This research and development has included iodine adsorption tests using a laboratory-scale test system containing segmented fixed beds of iodine adsorbents in series. Non-radioactive synthetic gas mixtures were blended from air, nitrogen, $\mathrm{NO}, \mathrm{NO}_{2}$, water, and the target iodine compounds to represent dissolver off-gas (DOG) streams from used nuclear fuel aqueous reprocessing. 
This page blank 


\section{TABLE OF CONTENTS}

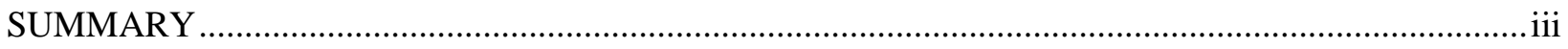

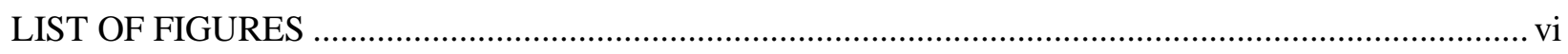

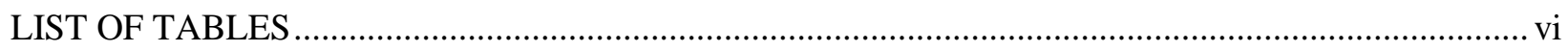

ACRONYMS AND ABBREVIATIONS ….......................................................................................... vii

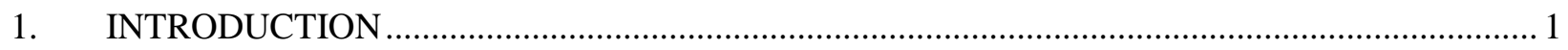

2. DEEP BED IODINE SORBENT TEST SYSTEM ................................................................... 1

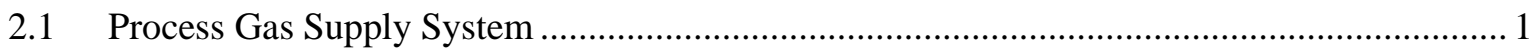

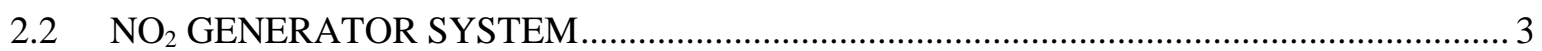

2.3 Sorbent Bed Segments ................................................................................................ 5

2.4 Sample Collection and Analysis ................................................................................ 7

2.4.1 Iodine Sample Collection and Analysis ................................................................. 7

2.4.2 Organic Compound Sampling and Analysis ....................................................... 7

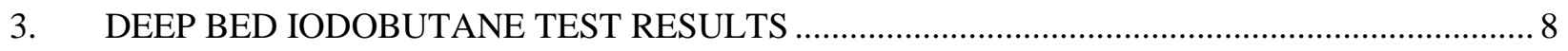

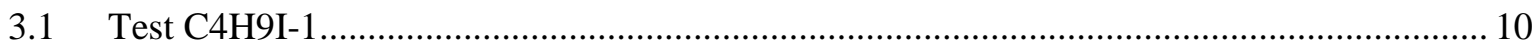

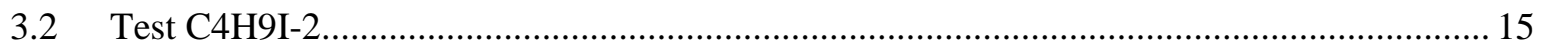

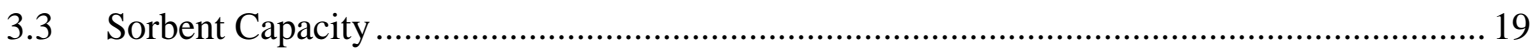

3.4 Byproduct Species in the Sorbent Bed Outlet Gas............................................................ 20

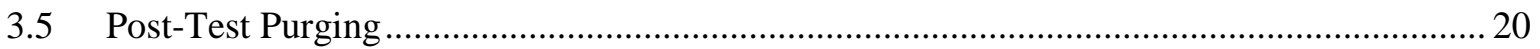

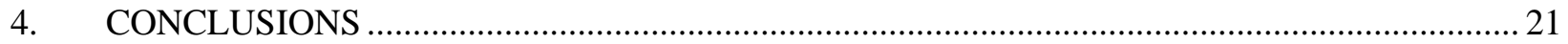

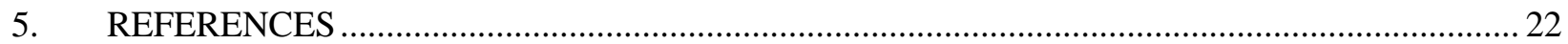




\section{LIST OF FIGURES}

Figure 2-1. Deep-bed adsorption test system

Figure 2-2. View of the 25-mL impingers for capturing water-soluble iodine species (left), the permeation tube generator system (middle), and water bath for the humidification system (right)....

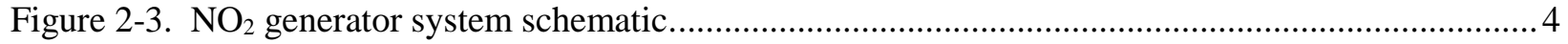

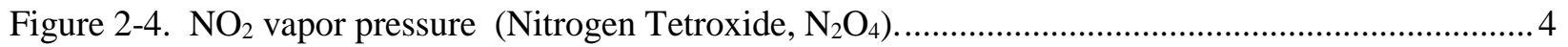

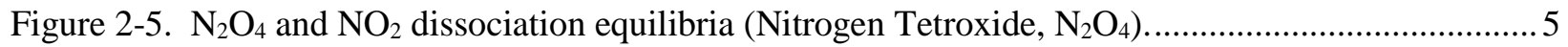

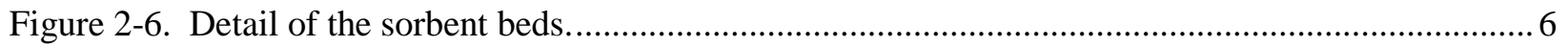

Figure 2-7. Configuration of the sorbent beds inside the temperature-controlled oven.............................. 6

Figure 3-1. Virgin Ag Aerogel at 25x magnification........................................................................... 10

Figure 3-2. AgA sorbent in the sorbent beds prior to the test C4H9I-1 ................................................ 11

Figure 3-3. AgA sorbent color change at about hour 70 in the C4H9I-1 test. ......................................... 11

Figure 3-4. Iodine-laden AgA sorbent in the following the 429-hr C4H9I-1 test. ................................. 11

Figure 3-5. Spent AgA from Bed 2 at 25x magnification................................................................ 11

Figure 3-6. Total iodine DF trends over time for Test C4H9I-1 ........................................................... 12

Figure 3-7. Iodobutane concentration trends over time for Test C4H9I-1 ............................................. 13

Figure 3-8. Bed segment outlet $\mathrm{I}_{2}$ concentration trends over time for Test C4H9I-1............................. 14

Figure 3-9. Bed segment outlet total iodine concentration trends over time for Test C4H9I-1................. 14

Figure 3-10. AgZ sorbent in the sorbent beds at hour 2.13 during test C4H9I-2. .................................... 16

Figure 3-11. AgZ sorbent in the sorbent beds at the end of the Test C4H9I-2 ....................................... 16

Figure 3-12. Total iodine DF trends over time for Test C4H9I-2 ......................................................... 17

Figure 3-13. Iodobutane concentration trends over time for Test C4H9I-2 ........................................... 17

Figure 3-14. Bed segment outlet $\mathrm{I}_{2}$ concentration trends over time for Test C4H9I-2 ............................ 18

Figure 3-15. Bed segment outlet total iodine concentration trends over time for Test C4H9I-2............... 19

Figure 3-16. Iodine loading and Ag utilization for the iodobutane adsorption tests.............................. 20

Figure 3-17. C4H9I-1 post-test sorbent purge results.............................................................................. 21

Figure 3-18. C4H9I-2 post-test sorbent purge results............................................................................ 21

\section{LIST OF TABLES}

Table 3-1. Results of the long-duration iodobutane tests....................................................................... 9

Table 3-2. MTZ depth estimates for Test C4H9I-1 .............................................................................. 12

Table 3-3. MTZ depth estimates for Test C4H9I-2. ........................................................................... 16 
ACRONYMS AND ABBREVIATIONS

$\begin{array}{ll}\text { AgA } & \text { silver aerogel } \\ \text { DF } & \text { decontamination factor } \\ \text { DL } & \text { detection limit } \\ \text { DOE } & \text { Department of Energy } \\ \text { DOG } & \text { dissolver off-gas } \\ \text { ECD } & \text { electron capture detector } \\ \text { EDS } & \text { energy dispersive spectroscopy } \\ \text { FID } & \text { flame ionization detector } \\ \text { FP } & \text { fission product } \\ \text { FY } & \text { fiscal year } \\ \text { GC } & \text { gas chromatograph } \\ \text { GCMS } & \text { gas chromatography with mass spectrometry } \\ \text { ICPMS } & \text { inductively coupled plasma mass spectrometry } \\ \text { INL } & \text { Idaho National Laboratory } \\ \text { MTZ } & \text { mass transfer zone } \\ \text { NTRD } & \text { Nuclear Technology Research and Development } \\ \text { SEM } & \text { scanning electron microscopy } \\ \text { SPME } & \text { solid-phase micro-extraction }\end{array}$


This page blank 


\section{INTRODUCTION}

The Department of Energy (DOE) Nuclear Technology Research and Development (NTRD) Program Material Recovery and Waste Form Development (MRWFD) Campaign Off-gas Sigma Team has supported research and development on iodine control and iodine waste forms for the past several years. This research and development has included iodine adsorption tests using a laboratory-scale test system containing multiple-segmented fixed beds of iodine adsorbents. Iodine capture performance has been tested using non-radioactive synthetic gas mixtures blended from air, nitrogen, $\mathrm{NO}, \mathrm{NO}_{2}$, water, and the target iodine compounds diatomic iodine $\left(\mathrm{I}_{2}\right)$, representing likely inorganic iodides, and methyl iodide (iodomethane, $\mathrm{CH}_{3} \mathrm{I}$ ) as a surrogate for potential organic iodides, that could exist in dissolver off-gas (DOG) and vessel off-gas (VOG) streams from used nuclear fuel aqueous reprocessing. Tests done in fiscal years 2017 and 2018 included synthetic gas mixtures containing n-iodobutane (n-butyl iodide, $\mathrm{C}_{4} \mathrm{H}_{9} \mathrm{I}$ ) in order to expand the evaluation of iodine capture to larger-chained organic iodides, likely to exist in DOG and VOG streams.

All work was performed in compliance with work control documentation that was updated in fiscal year (FY) 2014 to ensure data quality, worker safety, environmental protection, and regulatory compliance during testing (INL, 2015).

\section{DEEP BED IODINE SORBENT TEST SYSTEM}

Figure 2-1 shows a process diagram for the iodine test system. The test system consists of the following main components:

- Process gas supply and blending system, which supplies gases from gas cylinders, gas generators, and a humidifier

- Multiple sorbent bed system inside a heated oven

- Process gas bypass

- Inlet and bed segment outlet gas sampling system.

\subsection{Process Gas Supply System}

The process gas supply system consists of pressurized gas cylinders and gas generator systems that supply the gases that are blended together to make the gas mixture that is ultimately passed through the sorbent beds. These gases can include (depending on the test) pure air, nitrogen, $\mathrm{NO}, \mathrm{NO}_{2}$, water vapor, diatomic iodine, and organic iodine gas species. Air or $\mathrm{N}_{2}$ is supplied through mass flow controllers separately to the iodine and organic iodide generators, the humidifier, and the $\mathrm{NO}_{2}$ generator.

$\mathrm{NO}$ and $\mathrm{NO}_{2}$ gases, with balance $\mathrm{N}_{2}$, are supplied from compressed gas cylinders through mass flow controllers. When higher $\mathrm{NO}_{2}$ concentrations than can be obtained from ordinary compressed gas cylinders are required, an $\mathrm{NO}_{2}$ generator system that utilizes compressed liquefied $\mathrm{NO}_{2}\left(\mathrm{~N}_{2} \mathrm{O}_{4}\right)$ is used to supply the $\mathrm{NO}_{2}$.

Iodine gases are provided using compressed gas cylinders, permeation tubes, or a fixed bed iodine generator. The choice of gas source depends on the gas species and the flowrate needed to achieve the target concentration in the test gas mixture. For lower concentrations under about $30 \mathrm{ppmv}$ (depending on the gas), compressed gas cylinders or permeation tube systems can be used. For higher iodine concentrations, other generators can be used, such as a fixed bed of iodine crystals, interspersed in glass beads to prevent iodine crystal agglomeration, for $\mathrm{I}_{2}$ gas generation. 


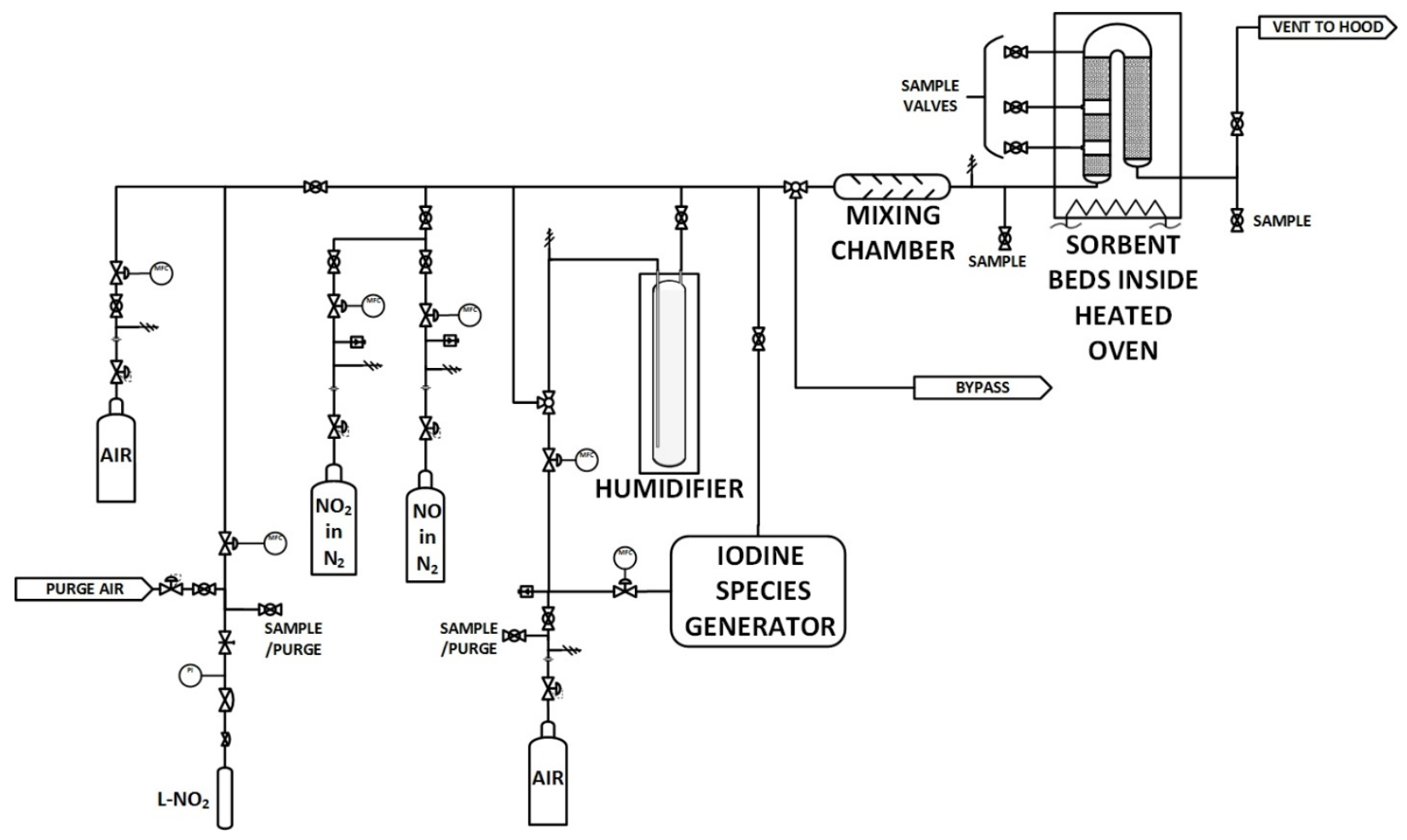

Figure 2-1. Deep-bed adsorption test system.

The iodobutane gas is generated from calibrated semi-permeable tubes of liquid iodobutane in a permeation tube system that maintains the permeation tubes at the temperature needed to provide the calibrated gas flowrate. The tubes (up to two), from VICI Metronics, are placed inside a Dynacalibrator Model 190 constant temperature permeation tube system (Figure 2-2) also from VICI Metronics.

Humidified air is produced by passing air or nitrogen through a fritted glass bubbler submerged in a constant temperature water bath. A thermocouple in the headspace of the bubbler provides the temperature of the water-saturated gas. The concentration of water in the blended gas is controlled by adjusting the gas flowrate through the humidifier and the humidifier operating temperature.

The gas flowrates and the generation rates of vaporized $\mathrm{NO}_{2}$, iodobutane, and water are set to achieve the target gas composition. The gases are blended in a mixing chamber upstream of the sorbent beds. All process lines that contain the vaporized $\mathrm{NO}_{2}$, iodobutane, and water, and the blended gases, are electrically heat traced. 


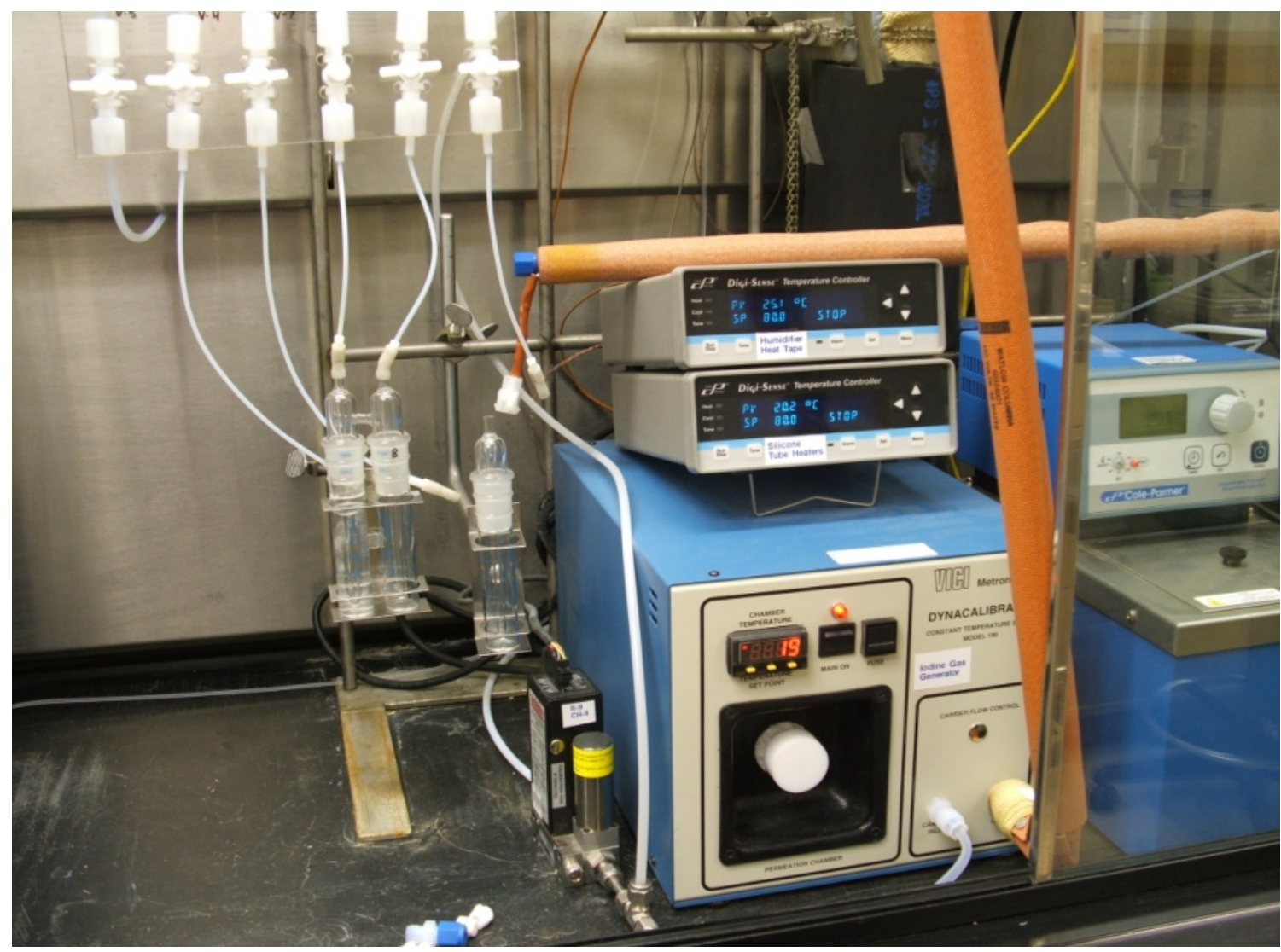

Figure 2-2. View of the 25-mL impingers for capturing water-soluble iodine species (left), the permeation tube generator system (middle), and water bath for the humidification system (right).

\section{$2.2 \mathrm{NO}_{2}$ GENERATOR SYSTEM}

From the recent Case Study ( (Law, et al., 2015)) and based on results of dissolver off-gas testing by Birdwell (Birdwell, 1991), benchmark total $\mathrm{NO}_{\mathrm{x}}$ levels in the dissolver off-gas stream downstream of a recycling condenser have been estimated at 1 volume \%, of which $\mathrm{NO}$ is $30 \%(3,000 \mathrm{ppmv})$ and $\mathrm{NO}_{2}$ is $70 \%(7,000 \mathrm{ppmv})$ of the total $\mathrm{NO}_{\mathrm{x}}$. Deep-bed iodine adsorption testing has not yet included evaporated $\mathrm{HNO}_{3}$, though there is a potential for evaporated $\mathrm{HNO}_{3}$ in the dissolver off gas (DOG) downstream of the condenser.

The amount of $\mathrm{NO}_{2}$ that can be provided in compressed gas cylinders is limited for the size of this bench-scale test system because higher $\mathrm{NO}_{2}$ concentrations in $\mathrm{N}_{2}$ are pressure-limited, and higher gas cylinder pressures have limited $\mathrm{NO}_{2}$ concentrations. It is not practical or cost-effective to use compressed gas cylinders of $\mathrm{NO}_{2}$ for long-duration deep-bed iodine adsorption testing with $\mathrm{NO}_{2}$ levels greater than about $1,000 \mathrm{ppmv}$ in gas streams at flowrates up to about $1 \mathrm{~L} / \mathrm{min}$.

The $\mathrm{NO}_{2}$ generator system (Figure 2-3) evaporates liquid $\mathrm{N}_{2} \mathrm{O}_{4}$ to produce gaseous $\mathrm{NO}_{2}$ for blending with the other gas streams that comprise the gas mixture for deep-bed iodine adsorption tests. In this system, the liquid $\mathrm{N}_{2} \mathrm{O}_{4}$ cylinder is mildly heated to no higher than $50^{\circ} \mathrm{C}$ (the safe operating limit for the cylinder) to create sufficient pressure in the cylinder (Figure 2-4) and provide heat for vaporizing the $\mathrm{N}_{2} \mathrm{O}_{4}$ and the endothermic conversion of $\mathrm{N}_{2} \mathrm{O}_{4}$ to $\mathrm{NO}_{2}$. Second, the conversion of gaseous $\mathrm{N}_{2} \mathrm{O}_{4}$ dimer to $\mathrm{NO}_{2}$ is assured by heating the gas stream to about $150^{\circ} \mathrm{C}$, which is the nominal operating temperature of 
the sorbent test bed system. At this temperature, the equilibrium constant for the conversion of $\mathrm{N}_{2} \mathrm{O}_{4}$ to $\mathrm{NO}_{2}$ favors $\mathrm{NO}_{2}$ (Figure 2-5) and facilitates $\mathrm{NO}_{2}$ flowrate monitoring and control.

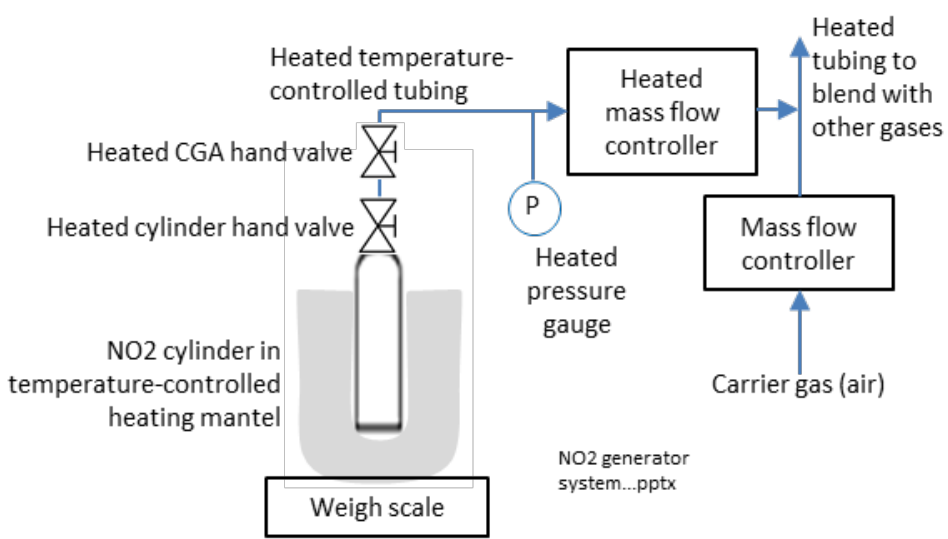

Figure 2-3. $\mathrm{NO}_{2}$ generator system schematic.

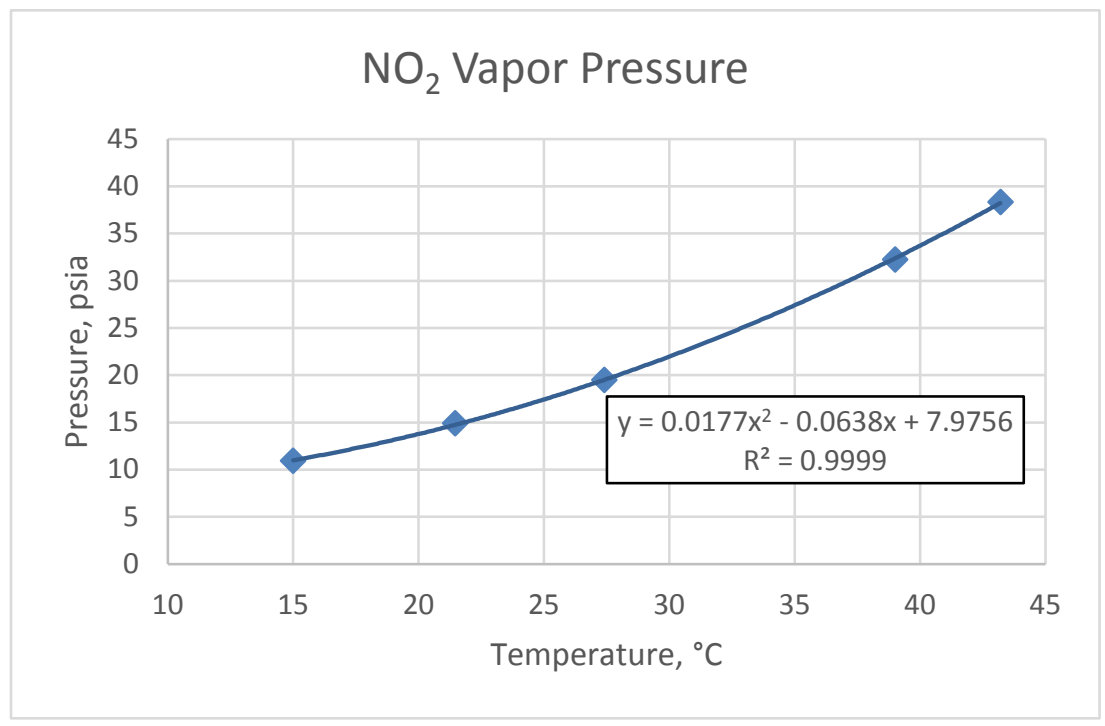

Figure 2-4. $\mathrm{NO}_{2}$ vapor pressure (Nitrogen Tetroxide, $\mathrm{N}_{2} \mathrm{O}_{4}$ ).

Initial testing indicated that the mass flow controller could not accurately control the $\mathrm{NO}_{2}$ gas flowrate, due to the uncertainty in the conversion of the gasified $\mathrm{N}_{2} \mathrm{O}_{4}$ to $\mathrm{NO}_{2}$ at the operating temperature of about $60^{\circ} \mathrm{C}$ for the mass flow controller. While the mass flow controller manages the instantaneous $\mathrm{NO}_{2}$ flowrate, the actual time-averaged $\mathrm{NO}_{2}$ flowrate is determined gravimetrically by weight change of the $\mathrm{N}_{2} \mathrm{O}_{4}$ cylinder.

The $\mathrm{NO}_{2}$ gas is promptly blended, after flowrate control, with the carrier gas to lower the $\mathrm{NO}_{2}$ concentration and prevent condensation. This blend of $\mathrm{NO}_{2}$ and carrier gas is then mixed with the rest of the gas mixture used in deep-bed iodine adsorption testing. 


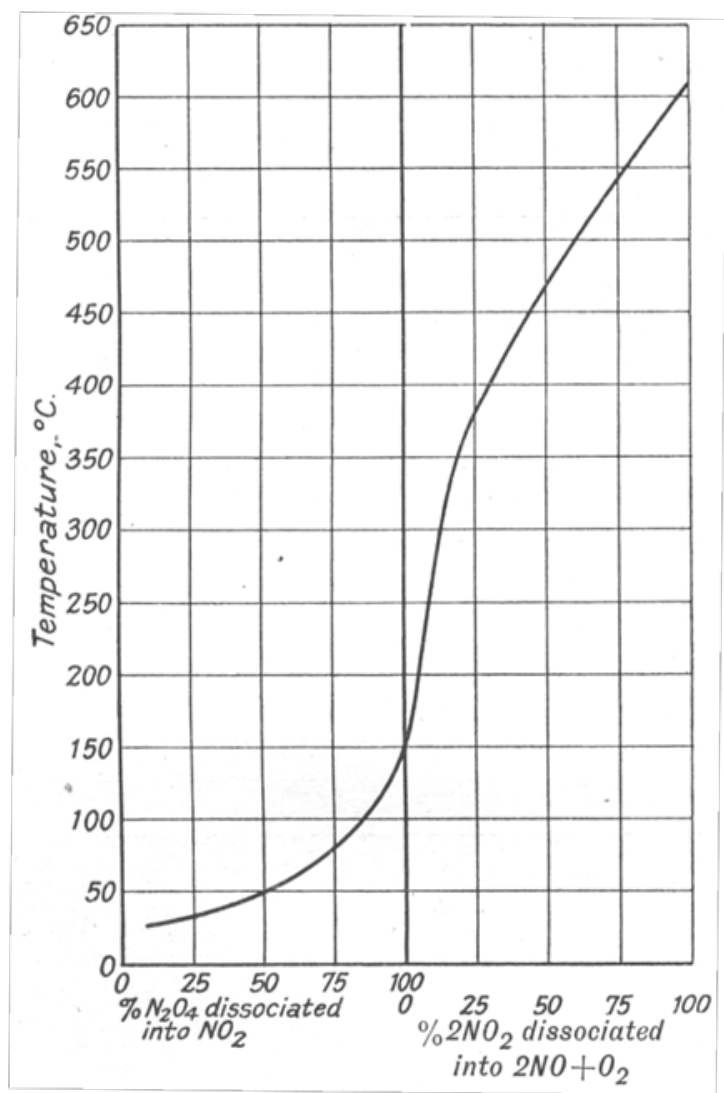

Figure 2-5. $\mathrm{N}_{2} \mathrm{O}_{4}$ and $\mathrm{NO}_{2}$ dissociation equilibria (Nitrogen Tetroxide, $\mathrm{N}_{2} \mathrm{O}_{4}$ ).

\subsection{Sorbent Bed Segments}

Figures 2-6 and 2-7 show detail of the sorbent beds and how the sorbent beds are configured in a temperature-controlled oven. The current test design includes up to four sorbent bed segments. The sorbent bed segments are made of borosilicate glass. A glass frit at the bottom of each bed segment supports the granular sorbent. 


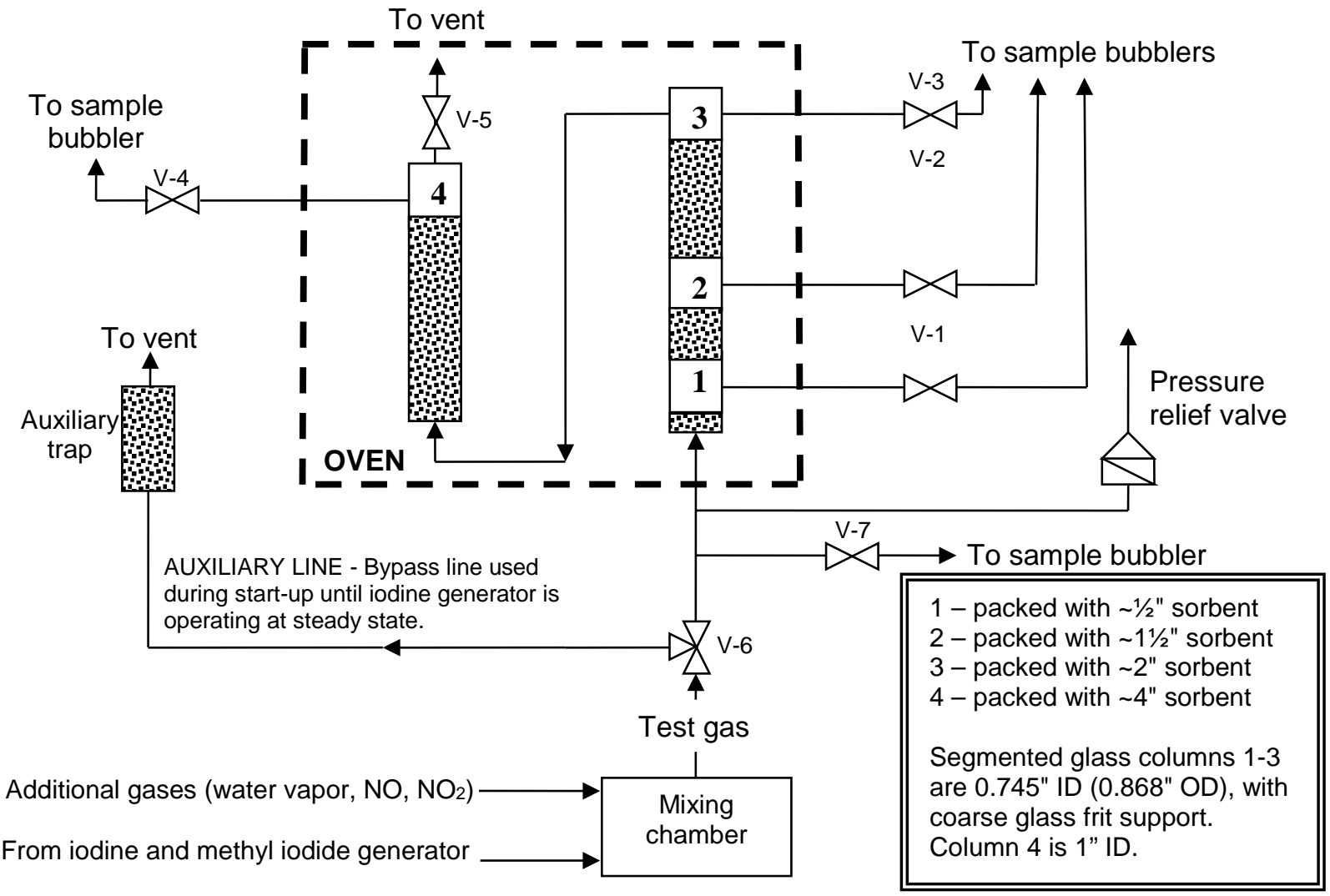

Figure 2-6. Detail of the sorbent beds.

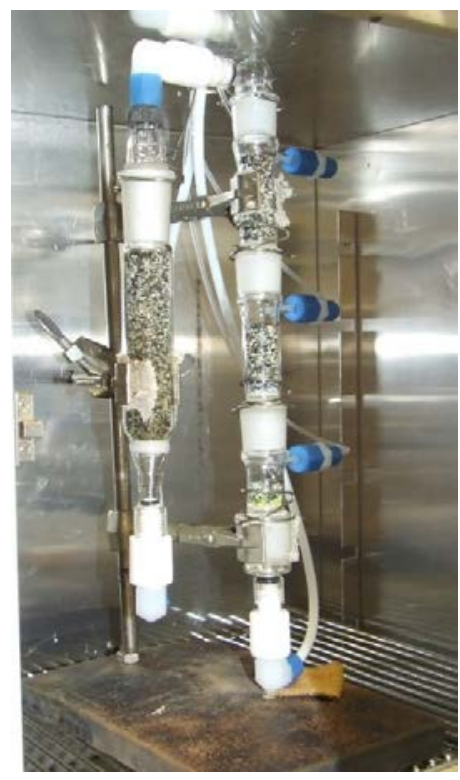

Figure 2-7. Configuration of the sorbent beds inside the temperature-controlled oven. 


\subsection{Sample Collection and Analysis}

The gas stream can be sampled for analysis at up to five locations in the test system - at the inlet to the sorbent bed segments, and at the outlet of each of up to four bed segments. Since the gas flowrate is essentially the same at all five sample locations, the removal efficiencies for the sorbent in all four beds can be determined by measuring the iodine gas species concentrations at these locations.

The iodine loadings and silver utilizations can be determined by several methods including (a) integration over time differences in the gaseous iodine concentrations for a given flowrate, (b) sorbent pre- and post-test gravimetric measurements, or (c) measurement of silver and adsorbed iodine using analytical methods such as scanning electron microscopy energy dispersive spectroscopy (SEM/EDS) or using wet chemistry methods of sorbent digestion followed by sample analysis. Using these methods for many tests has shown that the SEM/EDS method can provide the most reliable and quickest results. The SEM/EDS method, while subject to some experimental error, is not subject to (a) cumulative increasing experimental error observed in the gas analysis method, (b) experimental error in the gravimetric method due to relatively small weight changes and the potential for bias if the sorbent weight changes for other reasons such as the desorption or adsorption of other species, or (c) experimental error if some of the sorbent is not completely digested prior to analysis.

\subsection{1 lodine Sample Collection and Analysis}

Iodine measurements are made even when iodine is not included in the test gas mixture to determine if, or how much, iodine is being formed from reactions of the organic iodide.

For measuring the gaseous iodine concentration, the process gas from any of the five sample locations is passed through 25-mL "midget" impingers that contain $0.1 \mathrm{M} \mathrm{NaOH}$ for scrubbing halogen gases, including $\mathrm{I}_{2}$ and HI, if present. This technique is modeled after EPA Method 26 (Determination of Hydrogen Halide and Halogen Emissions from Stationary Sources, Non-Isokinetic Method, 2017). The caustic solution scrubs the halogens by hydrolyzing halogen gases to form a proton $\left(\mathrm{H}^{+}\right)$and hypohalous acid.

Any HI, if present, dissociates into the caustic solution, and is included with $\mathrm{I}_{2}$ in the analysis. Therefore, this test method does not discriminate between $\mathrm{I}_{2}$ and $\mathrm{HI}$ or other iodine species that are soluble in $0.1 \mathrm{M} \mathrm{NaOH}$.

The bubbler solutions are analyzed by inductively coupled plasma mass spectrometry (ICPMS) per EPA SW-846 (Method 6020A, 2015). The gaseous iodine detection limit (DL) is about 0.1-1 ppb with this method, depending on dilution during analysis. Higher-concentration samples for gas streams with 1 ppb or higher iodine concentrations are typically diluted for analysis.

\subsubsection{Organic Compound Sampling and Analysis}

Organic iodide analysis using gas chromatography (GC) has evolved over time due to the corrosive nature of the typical test gas. Early testing used a Hewlett-Packard model 5890 Series II gas chromatograph (GC) installed in-line with the sample loop, thereby allowing near real-time analysis of methyl iodide (Haefner \& Watson, 2010). An Rt-Q-BOND fused silica capillary column was used in the GC. The GC was equipped with an electron capture detector (ECD), which is very sensitive for measuring halogenated organic compounds. The minimum DL for this GC setup was about 5 ppb.

This early testing indicated that the use of the sample loop (which enables frequent and automatic sampling) and the highly sensitive ECD resulted in apparent corrosion of GC components, and erroneous 
measurements. The GC was frequently down for maintenance. Essentially all components that contacted the sample gas were eventually replaced, and the GC continued to malfunction frequently.

Beginning in FY-2013, the GC was replaced with another Hewlett Packard 5890 GC, equipped with a RTX-624, $30 \mathrm{~m}$ x $0.32 \mathrm{~mm}$ ID, 1.8- $\mu \mathrm{m}$ df column, and a flame ionization detector (FID). The sample loop was not used. This caused the sampling and analysis to be more operator time-intensive, and reduced the practical number of GC measurements, but also reduced the amount of time that the GC components are exposed to the corrosive sample gas.

The FID is not as sensitive for organic iodide analysis as the ECD. The organic iodide DL is about 1 ppm using direct injections. When lower DLs are desired, then a solid-phase micro-extraction (SPME) syringe is used. A SPME adsorbs organic compounds onto a solid-phase sorbent in a needle, thereby concentrating the amount of analyte. The adsorbed analytes are then desorbed into the GC carrier gas at an elevated temperature.

The SPME syringe is a Supelco brand, containing 75- $\mu$ m carboxen/polydimethylsiloxane fiber. The SPME and GC are calibrated together for specified adsorption and desorption times and temperatures. Using a SPME improves the methyl iodide DL for the FID by up to about 100x to approximately $10 \mathrm{ppb}$.

Unknown organic compounds formed by reactions of the organic iodide can appear as additional peaks on the GC-FID chromatograms. When this occurs, attempts are made to tentatively identify them using gas chromatography with mass spectroscopy (GCMS) analysis. The GCMS used for this work is a Shimadzu GC2010 with GCMS-QP2010 (with autosampler). The column is a J\&W Scientific DB-1 (dimethyl polysiloxane) column, $30 \mathrm{~m}$ x 0.25 mm ID x $1 \mu \mathrm{m}$ df.

\section{DEEP BED IODOBUTANE TEST RESULTS}

Two iodine adsorption tests were performed in time to be included in this report. These tests were performed consistent with the joint methyl iodide test plan (Jubin, Spencer, Soelberg, \& Strachan, 2015) except for using iodobutane instead of methyl iodide, in order to expand the organic iodide database. Table 3-1 summarizes the results of these tests. The target iodobutane concentration in the gas stream was 25 ppmv; the target $\mathrm{NO}$ and $\mathrm{NO}_{2}$ concentrations were 3,300 ppmv and 10,000 ppmv respectively. The moisture content was nominally 0.60 volume $\%$, corresponding to a dewpoint of $0^{\circ} \mathrm{C}$. 
Table 3-1. Results of the long-duration iodobutane tests.

\begin{tabular}{|c|c|c|}
\hline Run Number & C4H9I-1 Hi NOx AgA & C4H9I-2 Hi NOx AgZ \\
\hline Simulate what off-gas? & Dissolver & Dissolver \\
\hline Test start date & 26-Jul-17 & 7-Dec-17 \\
\hline \multicolumn{3}{|l|}{ Sorption conditions } \\
\hline Temperature, deg. C & 150 & 150 \\
\hline Total gas flowrate, $\mathrm{L} / \mathrm{min}$ & 0.74 & 0.74 \\
\hline Target bed inlet $\mathrm{C} 4 \mathrm{H} 9 \mathrm{I}$ conc, ppmv & 25 & 25 \\
\hline Average measured bed inlet $\mathrm{C} 4 \mathrm{H} 9 \mathrm{I}$ conc, ppmv & 26 & 20 \\
\hline Average measured bed inlet I2 conc, ppmv & 0.036 & 0.020 \\
\hline $\mathrm{H} 2 \mathrm{O}$ conc, $\%$ & $0.58 \%$ & $0.58 \%$ \\
\hline H2O dewpoint, deg. $\mathrm{C}$ & 0 & 0 \\
\hline NO conc., ppmv & 3,237 & 3,236 \\
\hline NO2 conc., ppmv & 9,675 & 10,013 \\
\hline Balance & air & air \\
\hline Sorption gas velocity, $\mathrm{m} / \mathrm{min}$ & 4.4 & 4.4 \\
\hline Depths of each successive orbent bed, inches & $0.5,1,2.5,4$ & $0.5,1,2.5,4$ \\
\hline Cumulative sorbent bed depths, inches & $0.5,1.5,4,8$ & $0.5,1.5,4,8$ \\
\hline Bed 1 out residence $t$, sec & 0.13 & 0.13 \\
\hline Bed 2 out cumulative residence $t$, sec & 0.43 & 0.43 \\
\hline Bed 3 out cumulative residence $t$, sec & 0.87 & 0.87 \\
\hline Bed 4 out cumulative residence $t$, sec & 2.25 & 2.25 \\
\hline Ag concentration from SEM/EDS, wt $\%$ & $25.3 \%$ & $13.5 \%$ \\
\hline Sorbent weight change, $\%$ & $0.9 \%$ & $0.2 \%$ \\
\hline Cumulative test duration, hrs & 429 & 282 \\
\hline lodine loadings from SEM/EDS & \multicolumn{2}{|c|}{$\%$ adsorbed iodine of mass of initial sorben } \\
\hline Bed 1 & $11.9 \%$ & $6.8 \%$ \\
\hline Bed 2 & $3.7 \%$ & $6.7 \%$ \\
\hline Bed 3 & $3.2 \%$ & $6.2 \%$ \\
\hline Bed 4 & $2.7 \%$ & $0.9 \%$ \\
\hline \multicolumn{3}{|l|}{ Silver utilization, $\%$} \\
\hline Bed 1 & $41 \%$ & $43 \%$ \\
\hline Bed 2 & $11 \%$ & $42 \%$ \\
\hline Bed 3 & $10 \%$ & $39 \%$ \\
\hline Bed 4 & $8.9 \%$ & $6.0 \%$ \\
\hline Max DF before breakthrough & 2,067 & 3,767 \\
\hline Average conversion of $\mathrm{C} 4 \mathrm{H} 9 \mathrm{I}$ to 12 in inlet gas & $0.28 \%$ & $0.19 \%$ \\
\hline Max conversion of bed outlet $\mathrm{C} 4 \mathrm{H} 9 \mathrm{I}$ to $\mathrm{I} 2$ & $99.9 \%$ & $99.97 \%$ \\
\hline Mass transfer zone depth, inches & 4 & 4 \\
\hline Organic compounds tentatively identified & \multicolumn{2}{|c|}{ None could be identified } \\
\hline
\end{tabular}

The degree to which iodobutane in the inlet gas stream was converted to other iodine species via gasphase reactions, prior to entering the sorbent bed segments, was determined by sampling the inlet gas stream for iodine species soluble in $0.1 \mathrm{M} \mathrm{NaOH}$, such as $\mathrm{HI}$ or $\mathrm{I}_{2}$. Analysis of the scrub solutions indicated less than $0.3 \%$ of the inlet $\mathrm{C}_{4} \mathrm{H}_{9} \mathrm{I}$ converted to $\mathrm{HI} / \mathrm{I}_{2}$. 


\subsection{Test C4H9l-1}

The sorbent used in this test was silver aerogel (AgA or Ag Aerogel) prepared by Pacific Northwest National Laboratory. According to SEM/EDS analysis, this sorbent contained an average of $25.3 \mathrm{wt} \%$ Ag.

Figure 3-1 shows the sorbent in the beds prior to adsorption testing. The virgin sorbent was dark black-reddish colored particles co-mingled with a few lighter colored particles. The maximum particle size was 1-2 mm. Some particles were under $1 \mathrm{~mm}$, and a few were under $0.1 \mathrm{~mm}$.

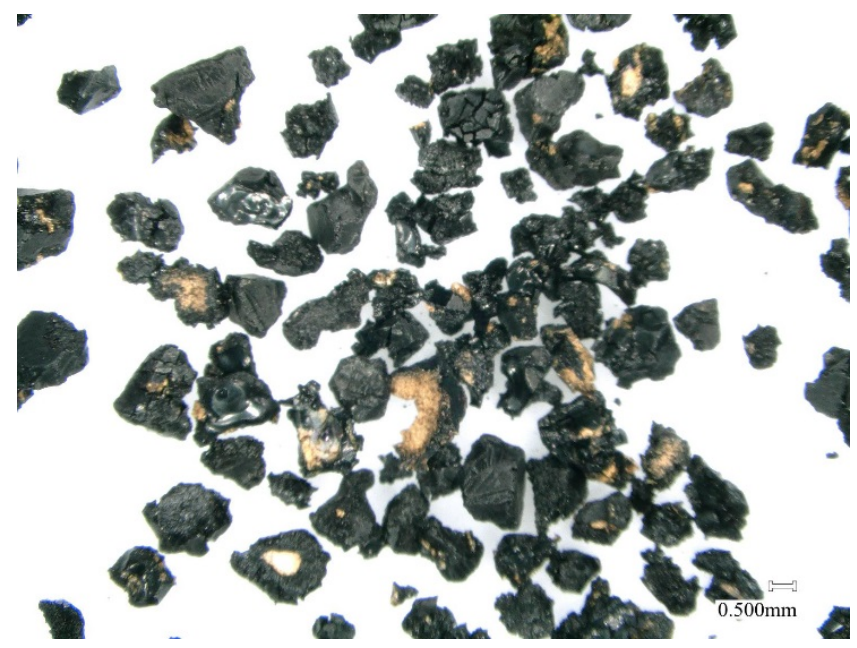

Figure 3-1. Virgin Ag Aerogel at 25x magnification.

Figures 3-2 through 3-4 show how the first, shallower beds change color first, as the iodine chemisorbs, or as gas constituents or reaction products of iodobutane decomposition adsorb on or otherwise react with the sorbent. As the dark sorbent color fades, the sorbent takes on a lighter, greenish tinge. This color change progresses through the beds for the test duration until, if the test runs long enough, color change occurs in all of the beds.

A post-test purge, intended to desorb and remove any weakly held iodine that was not chemisorbed on the sorbent, was performed at the end of the test. The sorbent color became uniformly lighter shades of white and grey. The sorbent in Bed 4, with the least amount of iodine adsorption, at the bottom of this down-flow bed, had the least color-change, as it still contained some particles that were quite dark colored.

Figure 3-5 shows that the AgA sorbent particles swelled during the test after extended exposure to test gases and iodine adsorption. Some of the particles fragmented during the test, resulting in visible amounts of particles less than $0.1 \mathrm{~mm}$ in diameter. Enough of these particles dispersed downstream of the sorbent beds to plug 1/8" full-port sample valves, requiring increased maintenance of the sample valves. The design and operation of larger scale iodine adsorption beds that use AgA may need to account for the potential of this fines generation. 


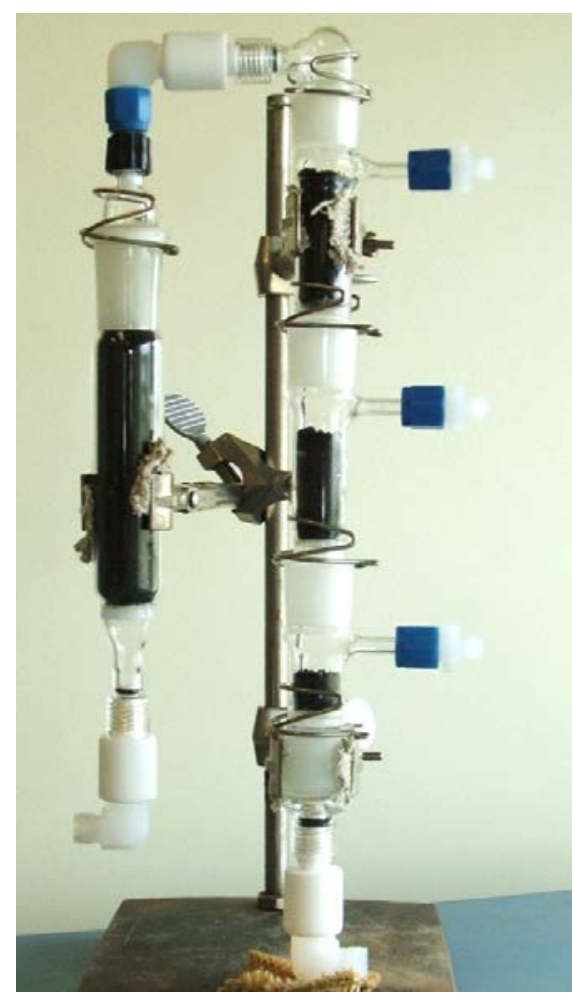

Figure 3-2. AgA sorbent in the sorbent beds prior to the test C4H9I-1.

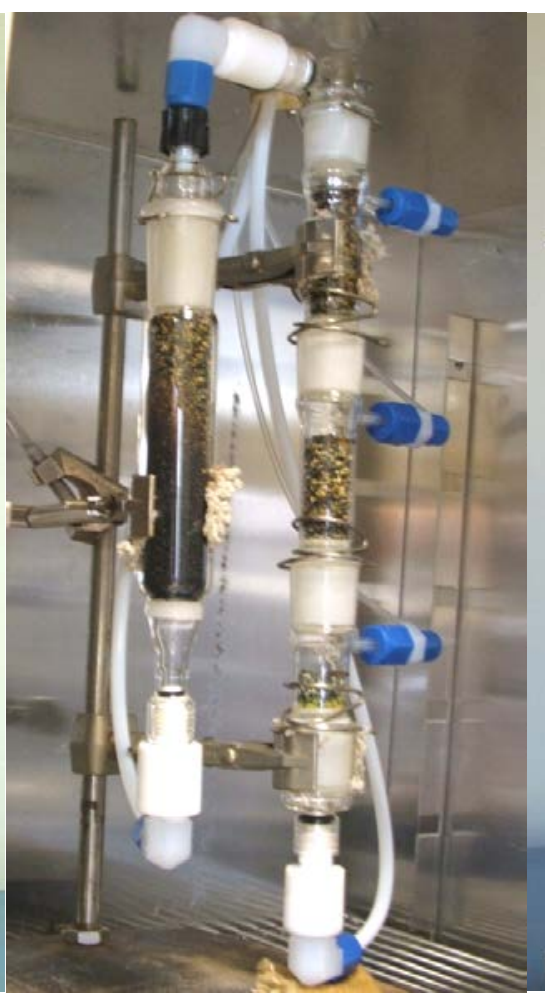

Figure 3-3. AgA sorbent color change at about hour 70 in the C4H9I-1 test.

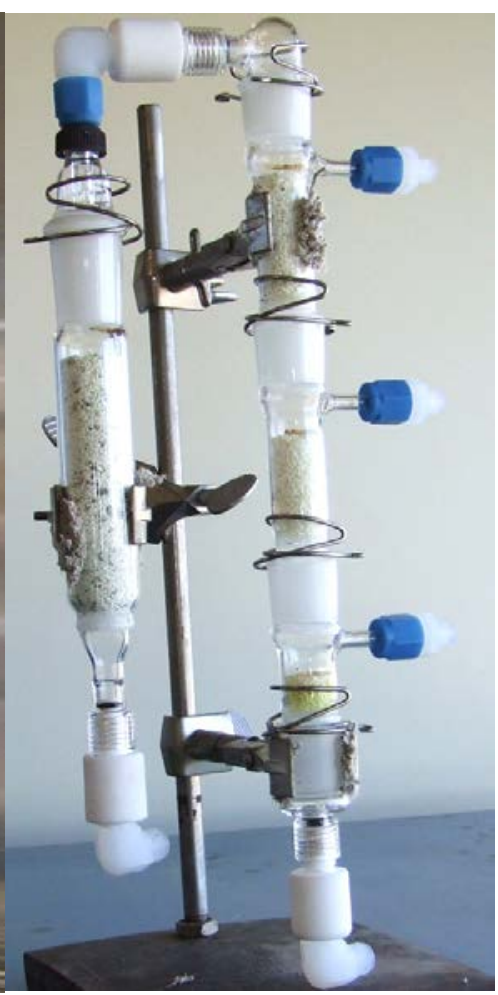

Figure 3-4. Iodine-laden AgA sorbent in the following the 429hr C4H9I-1 test.

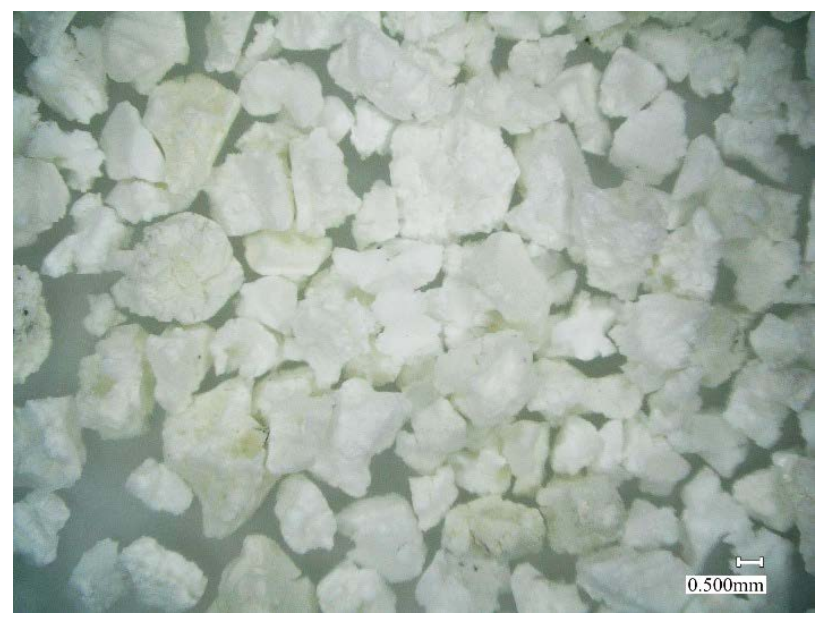

Figure 3-5. Spent AgA from Bed 2 at 25x magnification.

Figure 3-6 shows the measured decontamination factors (DFs) during this test. The DF is the ratio of the amount of total iodine measured in the bed inlet gas to the amount of total iodine measured in the bed outlet gas. Its relationship to the removal efficiency is:

$\mathrm{DF}=100 /(100-$ removal efficiency \%) 


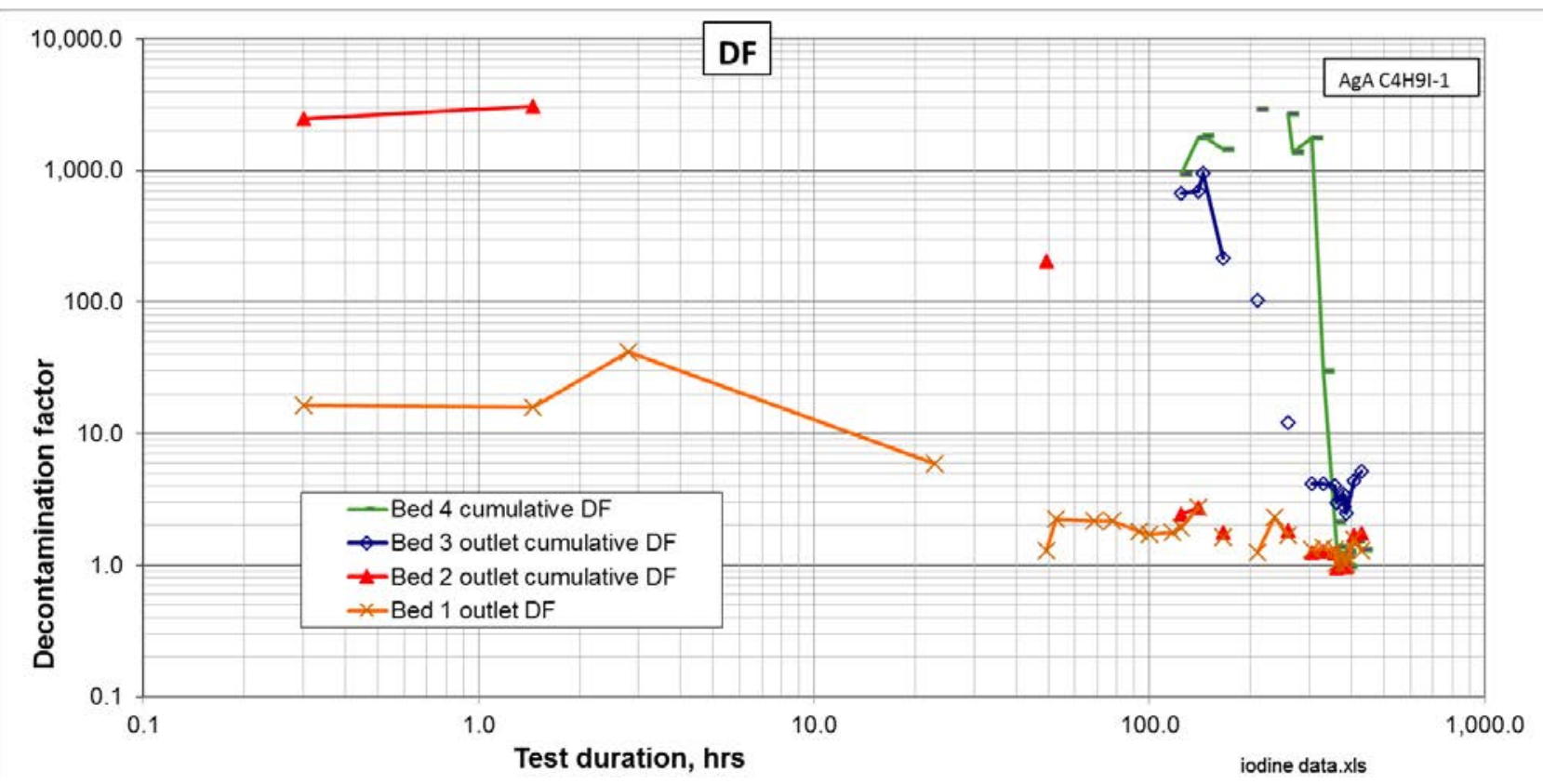

Figure 3-6. Total iodine DF trends over time for Test C4H9I-1.

This figure shows that the maximum DFs ranged between 2,000-3,000. This DF accounts for both the bed inlet and outlet iodobutane and iodides soluble in $\mathrm{NaOH}$ solution. Some of the data points were disqualified in post-test data quality checks, generally when either the inlet or outlet measurements for iodobutane or $\mathrm{I}_{2} / \mathrm{HI}$ concentration were not available. As expected, the 0.5 -in. deep Bed 1 outlet DF decreased most rapidly, and was never measured higher than about 10 . Bed 1 was so shallow that it was within the estimated depth of the mass transfer zone (MTZ) of about 4 inches for this test. Initial Bed 2 outlet DFs ranged as high as 3,000; but the total 2-in. depth of Beds 1 and 2 was also within the 4-in. MTZ depth, and so Bed 2 reached breakthrough after hour 1.5. Bed 3 reached breakthrough at about hour 145, and Bed 4 reached breakthrough at about hour 305. By about hour 360, all the beds became essentially saturated, with the DFs of Beds 1, 2, and 4 all approaching unity. The measured Bed 3 DF stabilized at about 3-5.

The MTZ depth was estimated for different test cumulative durations after about hour 120, when measurements are available for all four beds, as shown in Table 3-2. Breakthrough can be defined many ways; but in this estimation, breakthrough is defined to occur when the DF decreases below 1,000, which is the assumed nominal DF goal to comply with regulatory I-129 emission limits.

Table 3-2. MTZ depth estimates for Test C4H9I-1.

\begin{tabular}{|c|c|c|c|}
\hline $\begin{array}{c}\text { Cumulative } \\
\text { test time, hr }\end{array}$ & $\begin{array}{c}\text { Cumulative bed depth with DFs } \\
<1,000 \text { (DF value and depth, inches) }\end{array}$ & $\begin{array}{c}\text { Cumulative bed depth with DFs } \\
>1,000 \text { (DF value and depth, inches) }\end{array}$ & $\begin{array}{c}\text { Delta bed depth } \\
\text { (MTZ), in. }\end{array}$ \\
\hline 123 & 0.5 in. Bed 1, DF 2 & 4 in. Beds 1,2,3 DF 700 & 4 in. \\
& 2 in. Bed 1 + Bed 2, DF 2.5 & 8 in. Beds 1-4, DF 1,000 & 4 in. \\
\hline 310 & $\begin{array}{l}0.5 \text { in. Bed 1, DF 1.2 } \\
\text { 2 in. Bed 1 + Bed 2, DF 1.3 } \\
\text { 4 in. Beds 1,2,3 DF 4 }\end{array}$ & A in. Beds 1-4, DF 1,000 \\
\hline \multicolumn{3}{|r|}{ Average } & 4 in. \\
\hline
\end{tabular}

The iodobutane measurement trends are shown in Figure 3-7. This figure shows that initial bed outlet iodobutane concentrations decreased by about one order of magnitude for Bed 1 and about four orders of 
magnitude for the other, deeper bed segments. Bed 1 outlet iodobutane concentrations ranged between about 0.2-2 ppmv for the duration of the test. This shows that even when Bed 1 became effectively saturated and the Bed 1 DF approached unity, reactions in Bed 1 reduced the iodobutane concentration by 92-99\%.

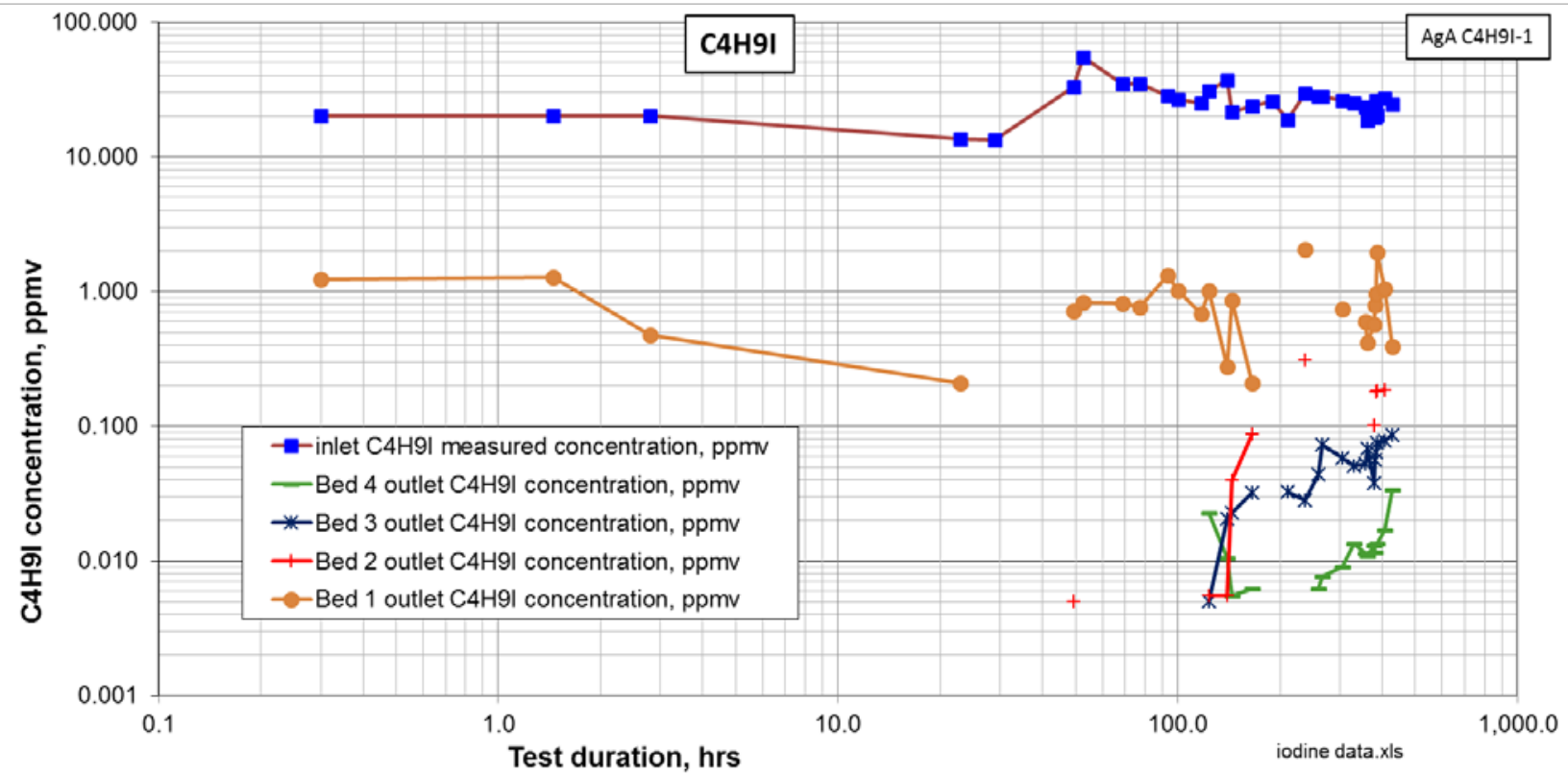

Figure 3-7. Iodobutane concentration trends over time for Test C4H9I-1.

The iodobutane concentrations at the outlets of Beds 2, 3, and 4 ranged as low as about 0.005 ppmv (the iodobutane detection limit), consistent with the initially high total DFs of up to 3,000. By the test end, the Bed 2 iodobutane concentration increased to about 0.2-0.3 ppmv; the Bed 3 iodobutane concentration increased to about $0.09 \mathrm{ppm}$; and the Bed 4 iodobutane concentration increased to about 0.03 ppmv. None of these concentrations is consistent with the test-end DFs for those beds of between 15. This is because, through the total 8-in. deep combined bed depth, the iodobutane was nearly completely destroyed to an efficiency of about $99.9 \%$, even though the iodine adsorption stopped near the end of the 429-hr test.

Figure 3-8 shows that, as the test progressed, iodine that was not adsorbed by the sorbent beds passed out of the sorbent beds primarily as $\mathrm{I}_{2}$ and $\mathrm{HI}$, reported as $\mathrm{I}_{2}$. The initial bed outlet $\mathrm{I}_{2}$ concentrations ranged between 0.001-0.01 ppmv, up to four orders of magnitude less than the inlet iodobutane concentrations, consistent with the initial overall iodobutane DFs of up to 3,000.

Bed 1 outlet $\mathrm{I}_{2}$ concentrations increased to about $10 \mathrm{ppmv}$ by about hour 50, and remained about 7-10 ppmv for the remainder of the test. Bed 2 outlet $\mathrm{I}_{2}$ concentrations reached about 8 ppmv by about hour 120 , and remained at 7-8 ppmv for the remainder of the test. Bed 3 and Bed 4 outlet $\mathrm{I}_{2}$ concentrations fluctuated somewhat after about hour 50; but Bed 2 outlet $\mathrm{I}_{2}$ concentrations trended between 0.02-1 ppmv before rising to 1 ppmv by test-end. Bed 4 outlet $I_{2}$ concentrations rose consistently with Bed 2 and 3 outlet $\mathrm{I}_{2}$ concentrations until about hour 50, after which it decreased to about $0.002 \mathrm{ppmv}$, even lower than its initial $\mathrm{I}_{2}$ concentration. The reason for these fluctuating Bed 3 and 4 outlet $\mathrm{I}_{2}$ concentrations is not clear at this time.

These figures show that the major contributor to decreasing total iodine DFs was the formation of iodine species reported as $\mathrm{I}_{2}$, not remaining iodobutane. 


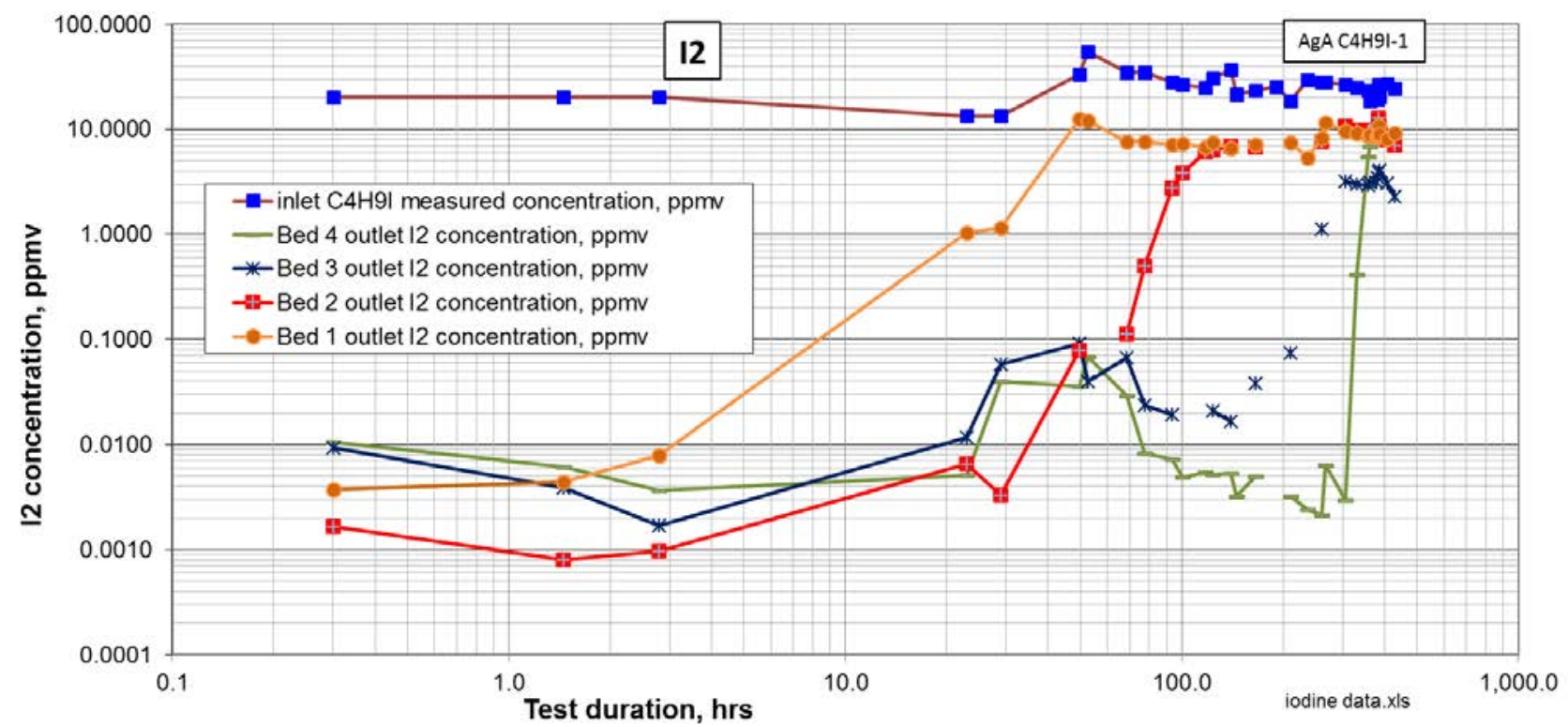

Figure 3-8. Bed segment outlet $\mathrm{I}_{2}$ concentration trends over time for Test C4H9I-1.

Figure 3-9 compares the inlet iodobutane concentrations and outlet total $\mathrm{I}_{2}$ and iodobutane concentrations (normalized to total iodobutane) as the test progressed. In this figure, the diatomic $\mathrm{I}_{2}$ concentration has been normalized to the monatomic iodine form, for direct comparison to the inlet iodobutane concentration. Chemical reactions occurred as the gas mixture passed through the sorbent bed that breaks up the iodobutane molecule; and allowed adsorption of iodine, until the sorbent capability was depleted, at which time the non-adsorbed iodine remained in the gas stream as iodine species that are soluble in an $\mathrm{NaOH}$ solution. By test end, about $99.9 \%$ of the non-adsorbed measured iodine was not iodobutane, but iodine species that were soluble in the $\mathrm{NaOH}$ scrubber solution.

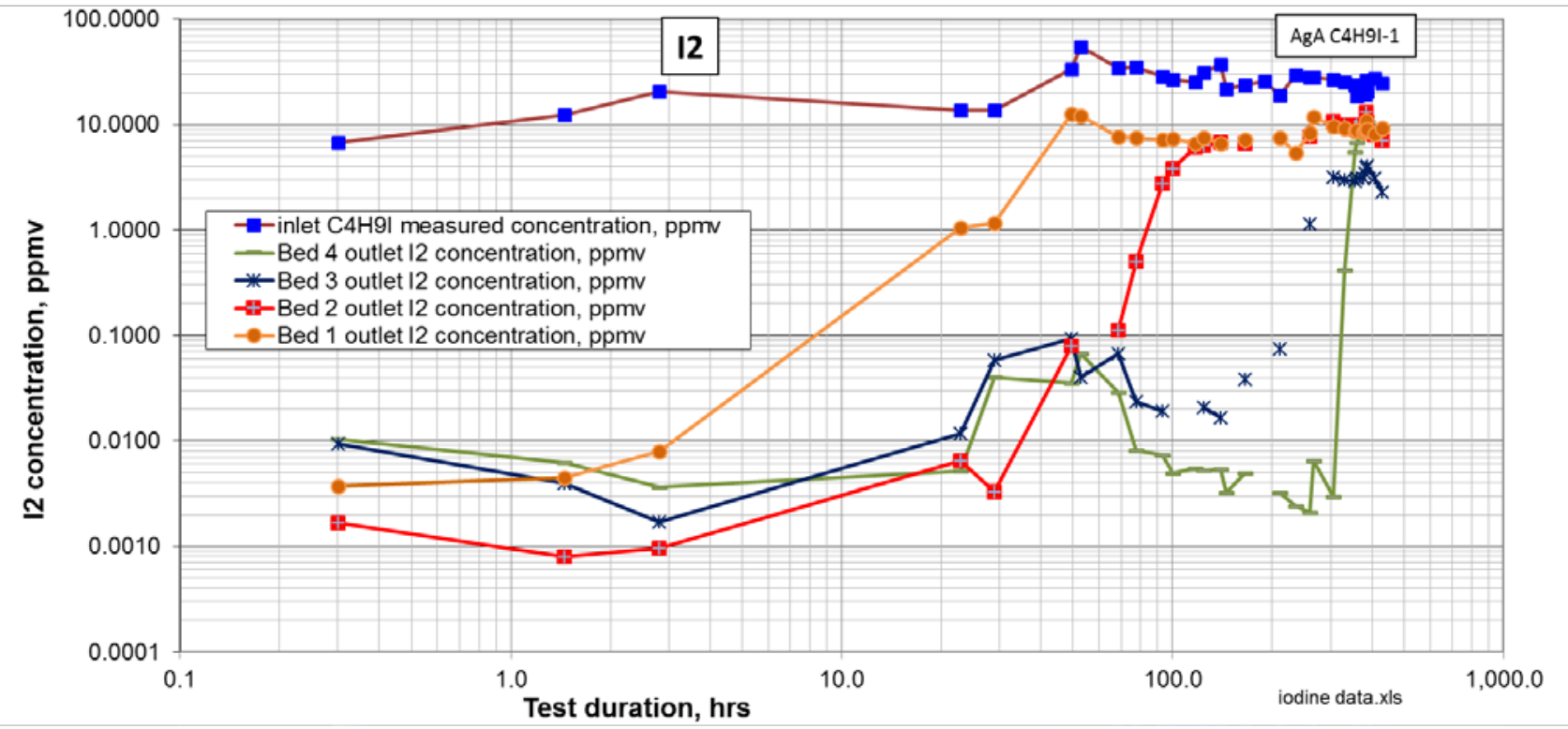

Figure 3-9. Bed segment outlet total iodine concentration trends over time for Test C4H9I-1.

Consistent with data presented in the prior figures, the initial bed outlet total normalized monatomic iodine concentrations (reported as iodobutane) ranged from one to four orders of magnitude less than the 
inlet iodobutane concentrations, consistent with the initial DFs up to 3,000. By about hour 20, the bed outlet total iodobutane concentrations increased; until by hour 50, total Bed 1 outlet iodobutane concentration reached about 25 ppmv, and then stayed between about 15-20 ppmv for the remainder of the test. The Bed 2 outlet total iodobutane concentration increased to about 15 ppmv by hour 200, and to 20 ppmv by hour 400 . The Bed 4 outlet total iodobutane concentration also increased to about 20 ppmv by hour 400 .

While the measured total bed outlet normalized iodobutane concentrations ranged up to $20 \mathrm{ppmv}$ towards the end of the test, this value still averaged about $20 \%$ less than the $\sim 25$ ppmv iodobutane concentration at the bed inlet. Either some other iodine species, not identified by the GC and not captured in the caustic scrubbers, was formed; or this difference may be attributable to experimental error between the bed inlet and outlet measurements.

\subsection{Test C4H9I-2}

The sorbent used in this test was silver zeolite (AgZ) prepared by Oak Ridge National Laboratory. The silver in this sorbent was chemically reduced to $\mathrm{Ag}^{\circ}$ by treatment with a hot $\mathrm{H}_{2}$ gas mixture. According to SEM/EDS analysis, this sorbent contained an average of $13.5 \mathrm{wt} \% \mathrm{Ag}$.

Figure 3-10 shows the sorbent in the sorbent beds after 2.1 hours of test operation. The virgin AgZ is a mixture of mostly darker brown colored pellets as shown in the 4-in. long Bed 4 in this photo. After just two hours of test operation, much of the 0.5-in. deep Bed 1 turned a light green color, which has typically indicated iodine adsorption in prior tests. Most of Beds 2 and 3, the inlet portion of Bed 4, have turned from the dark brown color to a light grey color. This is also typical of prior tests, and may be a result of exposure of the sorbent to $\mathrm{NO}_{\mathrm{x}}$ or moisture in the gas stream, along with expectedly only a small amount of iodine adsorption. Most of the iodine at this early stage in the test would have been adsorbed in Bed 1, although Beds 2 and 3 may also be in the MTZ and so may have a small amount of adsorbed iodine.

Figure 3-11 shows the sorbent at the end of the 282-hr C4H9I-2 test. The sorbent in Beds 1-3 and the top portion of Bed 4 turned a medium green color, suggestive of iodine adsorption to near capacity as seen in prior iodine adsorption tests. The sorbent in the lower portion of Bed 4, with the least amount of iodine adsorption, at the bottom of the down-flow fourth bed, had the least color-change, as it had turned from the initial dark brown color to a lighter grey-green color, but not to the medium green color.

Figure 3-12 shows that the maximum DFs for this test ranged between 2,000-6,000. This DF accounts for both the bed inlet and outlet iodobutane and iodides soluble in $\mathrm{NaOH}$ solution. As expected, the 0.5-in. deep Bed 1 outlet DF decreased most rapidly, and was never measured higher than about 800. Bed 1 was so shallow that it was within the estimated depth of the MTZ and so could never achieve the maximum DF. Bed 2 outlet DFs ranged above 1,000 until about hour 10. Bed 3 reached breakthrough at about hour 100, and Bed 4 never reached breakthrough during the duration of this $282 \mathrm{hr}$ test.

The MTZ depth was estimated at test hours 10, 100, and 282 in Table 3-3. While the MTZ at hour 10 was only about 2 inches, this shallow depth is not representative, so early in the test. Breakthrough is defined for this test to occur when the DF decreases below 1,000, which is the assumed nominal DF goal to comply with regulatory I-129 emission limits. The MTZ was estimated at 4 inches at hours 100 and 282. 


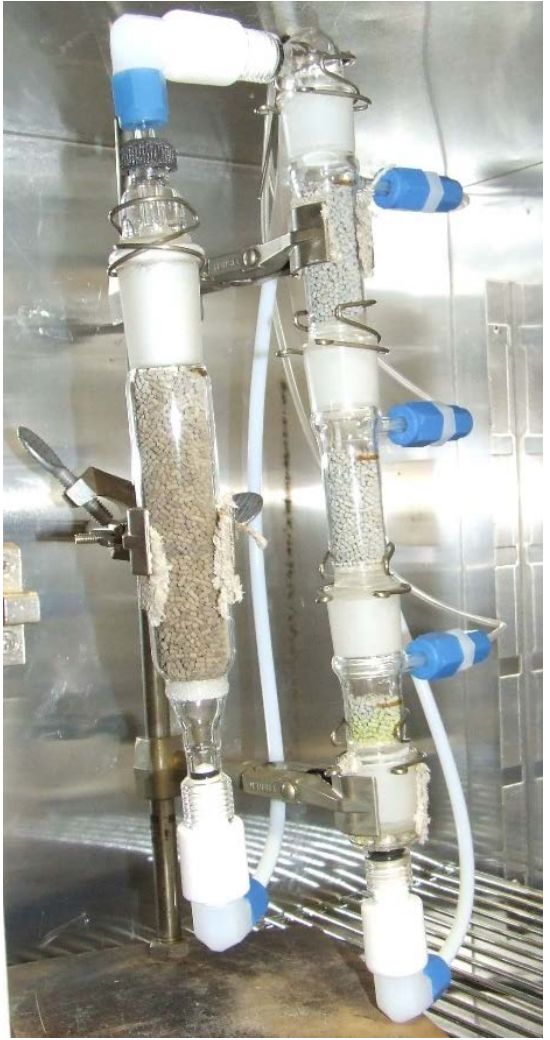

Figure 3-10. AgZ sorbent in the sorbent beds at hour 2.13 during test C4H9I-2.

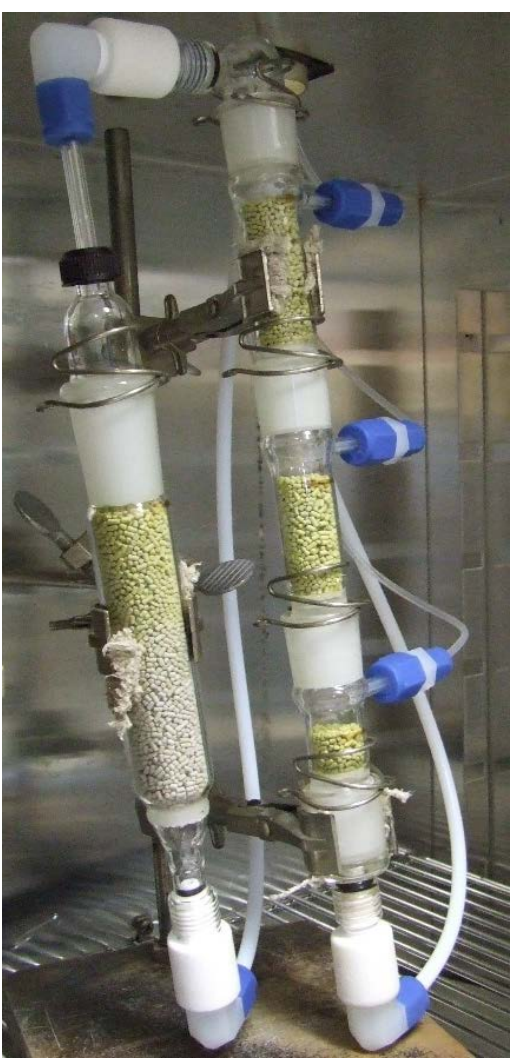

Figure 3-11. AgZ sorbent in the sorbent beds at the end of the Test C4H9I-2.

Table 3-3. MTZ depth estimates for Test C4H9I-2.

\begin{tabular}{|c|c|c|c|}
\hline $\begin{array}{l}\text { Cumulative } \\
\text { test time, hr }\end{array}$ & $\begin{array}{c}\text { Cumulative bed depth with DFs } \\
<1,000 \text { (DF value and depth, inches) }\end{array}$ & $\begin{array}{c}\text { Cumulative bed depth with DFs } \\
>1,000 \text { (DF value and depth, inches) }\end{array}$ & $\begin{array}{l}\text { Delta bed depth } \\
\text { (MTZ), in. }\end{array}$ \\
\hline 10 & 0.5 in. Bed 1, DF 5 & $\begin{array}{l}2 \text { in. Bed 1 + Bed 2, DF 1,000 } \\
4 \text { in. Beds 1,2,3 DF 1,000 } \\
8 \text { in. Beds 1-4, DF 3,000 }\end{array}$ & 2 \\
\hline 100 & $\begin{array}{l}0.5 \text { in. Bed 1, DF 1.4 } \\
2 \text { in. Bed 1 + Bed 2, DF 3 } \\
4 \text { in. Beds 1,2,3 DF 4 }\end{array}$ & $\begin{array}{l}4 \text { in. Beds 1,2,3 DF 1,000 } \\
8 \text { in. Beds 1-4, DF 4,000 } \\
8 \text { in. Beds 1-4, DF 1,000 }\end{array}$ & 4 \\
\hline 282 & $\begin{array}{l}0.5 \text { in. Bed 1, DF 1 } \\
2 \text { in. Bed 1 + Bed 2, DF 1 } \\
4 \text { in. Beds 1,2,3 DF 1.5 }\end{array}$ & 8 in. Beds 1-4, DF 4,000 & 4 \\
\hline & & Average & $\begin{array}{l}4 \text { (not including } \\
\text { the } 10 \text {-hr MTZ, } \\
\text { early in the test) }\end{array}$ \\
\hline
\end{tabular}




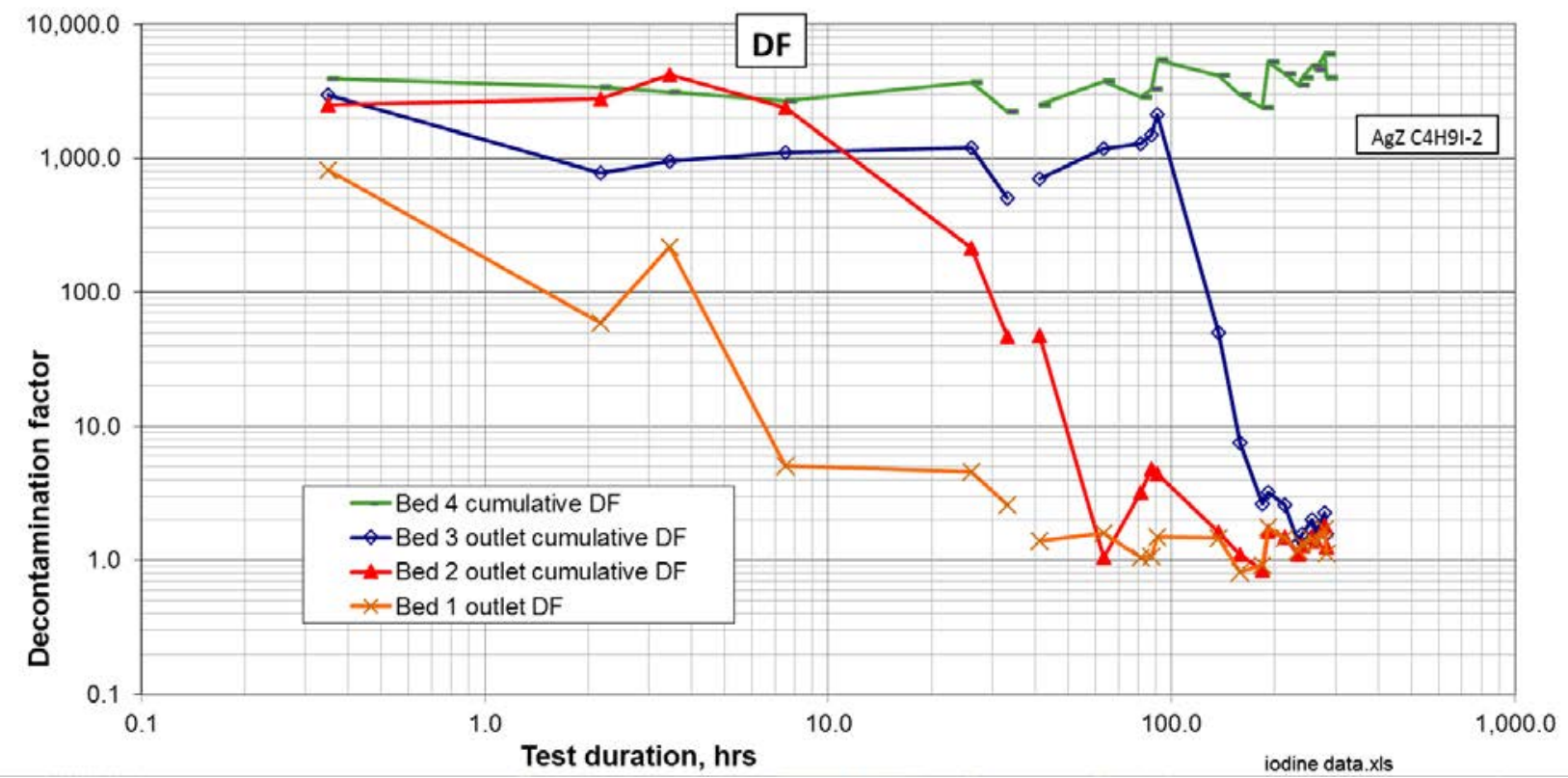

Figure 3-12. Total iodine DF trends over time for Test C4H9I-2.

Iodobutane measurement trends are shown in Figure 3-13. The inlet iodobutane concentration ranged between about 10-30 ppmv, and averaged 20 ppmv. Bed 1 outlet iodobutane concentrations ranged from non-detectable to about 2 ppmv at the end of the test. Even after Bed 1 reached iodine saturation, over $90 \%$ of the inlet iodobutane was destroyed when it passed through Bed 1. No iodobutane was detected at the Bed 2, 3, and 4 outlets, at a detection limit of about 0.005 ppmv, for the entire duration of the test. Essentially all (>99.98\%) of the iodobutane was destroyed by the time it passed through the cumulative 2in. depth of Beds 1 and 2, regardless of the adsorption of the iodine in those beds.

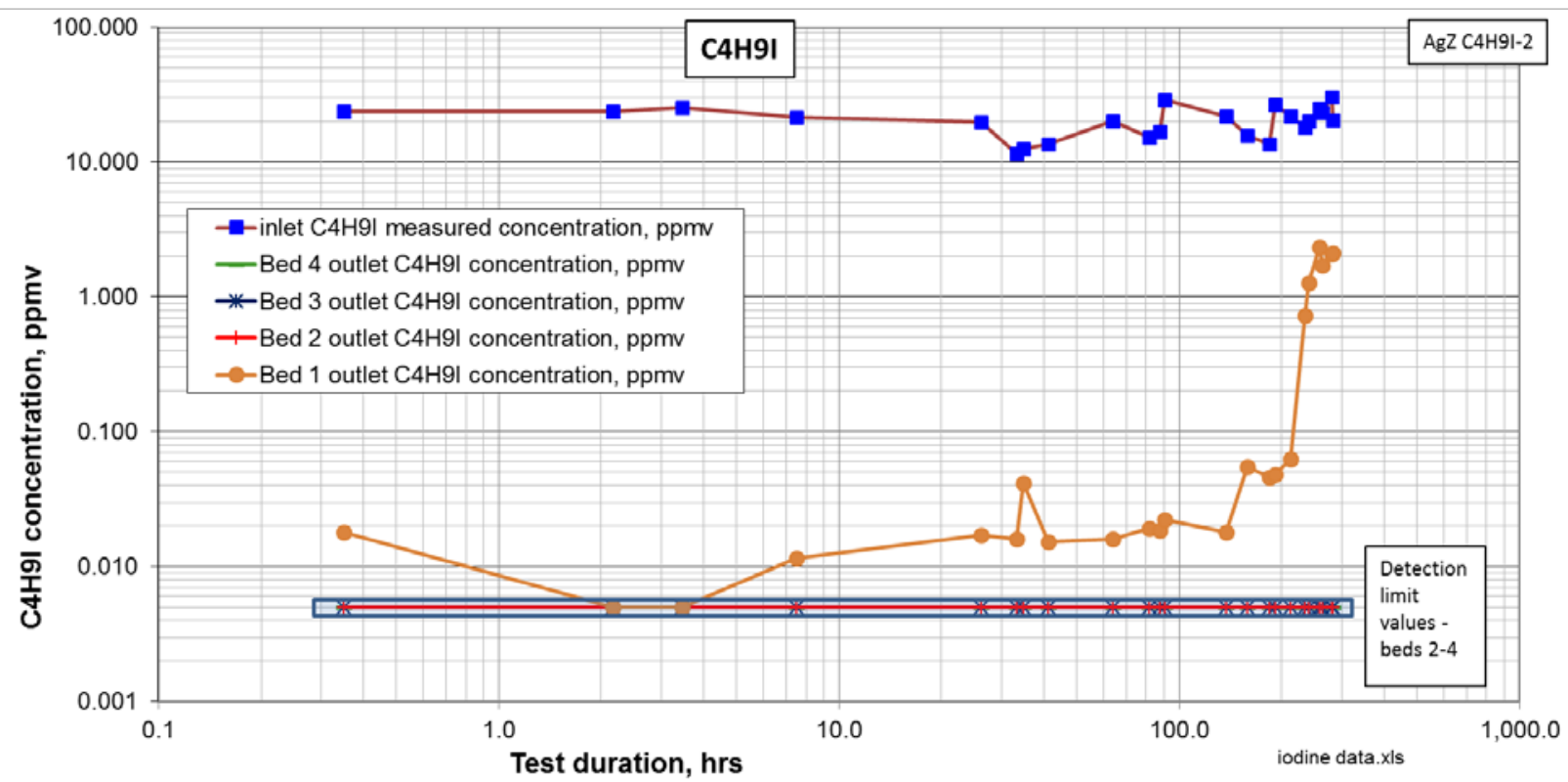

Figure 3-13. Iodobutane concentration trends over time for Test C4H9I-2. 
Figure 3-14 shows that, as the test progressed, iodine that was not adsorbed by the sorbent beds passed out of the sorbent beds primarily as $\mathrm{I}_{2}$ and $\mathrm{HI}$, reported as $\mathrm{I}_{2}$. The initial bed outlet $\mathrm{I}_{2}$ concentrations ranged between $0.0005-0.005$ ppmv, up to five orders of magnitude less than the inlet iodobutane concentrations, consistent with the initial overall DFs of up to 6,000.

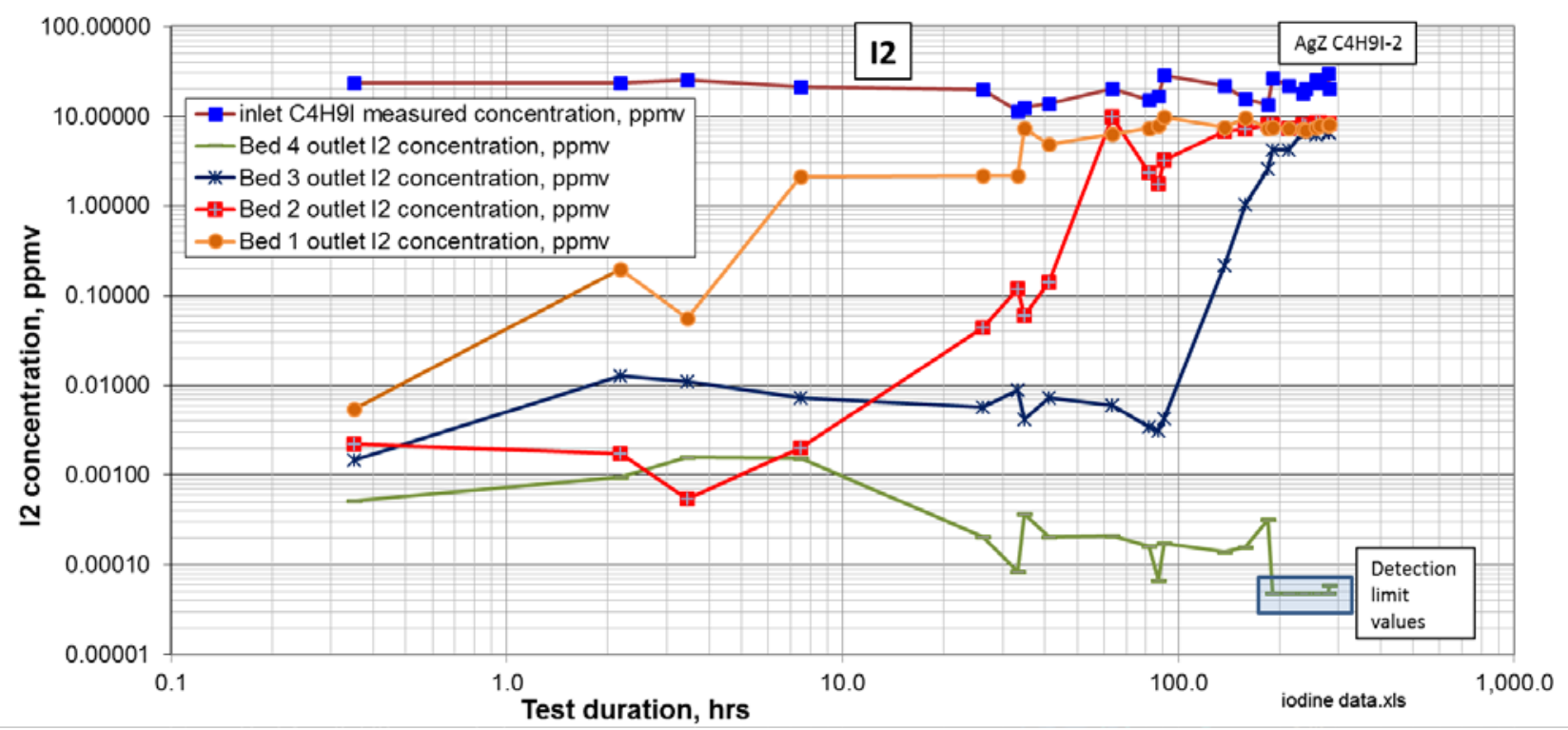

Figure 3-14. Bed segment outlet $\mathrm{I}_{2}$ concentration trends over time for Test C4H9I-2.

As the test progressed, the $I_{2}$ concentrations generally increased. Bed 1 outlet $I_{2}$ concentrations increasing the soonest and fastest, from about 0.005 ppmv to 8-10 ppmv by test end. Bed 2 outlet $\mathrm{I}_{2}$ concentrations ranged around $0.002 \mathrm{ppmv}$ until about hour 8 , when the concentrations increased to about 8-10 ppm by test end. Bed $3 \mathrm{I}_{2}$ concentrations ranged around 0.002 to $0.01 \mathrm{ppmv}$ until about hour 100 , when the concentrations increased to about 6-7 ppm by test end. Bed 4 outlet $\mathrm{I}_{2}$ concentrations ranged between about 0.0001 to $0.002 \mathrm{ppm}$ for the duration of the test, even decreasing to non-detectable values near the end of the test.

These figures show that the major contributor to decreasing total iodine DFs was the formation of iodine species reported as $\mathrm{I}_{2}$, not remaining iodobutane.

Figure 3-15 compares the inlet iodobutane concentrations and outlet total $\mathrm{I}_{2}$ and iodobutane concentrations (normalized to total iodobutane) as the test progressed. In this figure, the diatomic $\mathrm{I}_{2}$ concentration has been normalized to the monatomic iodine form, for direct comparison to the inlet iodobutane concentration. Chemical reactions occurred as the gas mixture passed through the sorbent bed that breaks up the iodobutane molecule; and allowed adsorption of iodine, until the sorbent capability was depleted, at which time the non-adsorbed iodine remained in the gas stream as iodine species that are soluble in an $\mathrm{NaOH}$ solution. By test end, about $99.9 \%$ of the non-adsorbed measured iodine was not iodobutane, but iodine species that were soluble in the $\mathrm{NaOH}$ scrubber solution. 


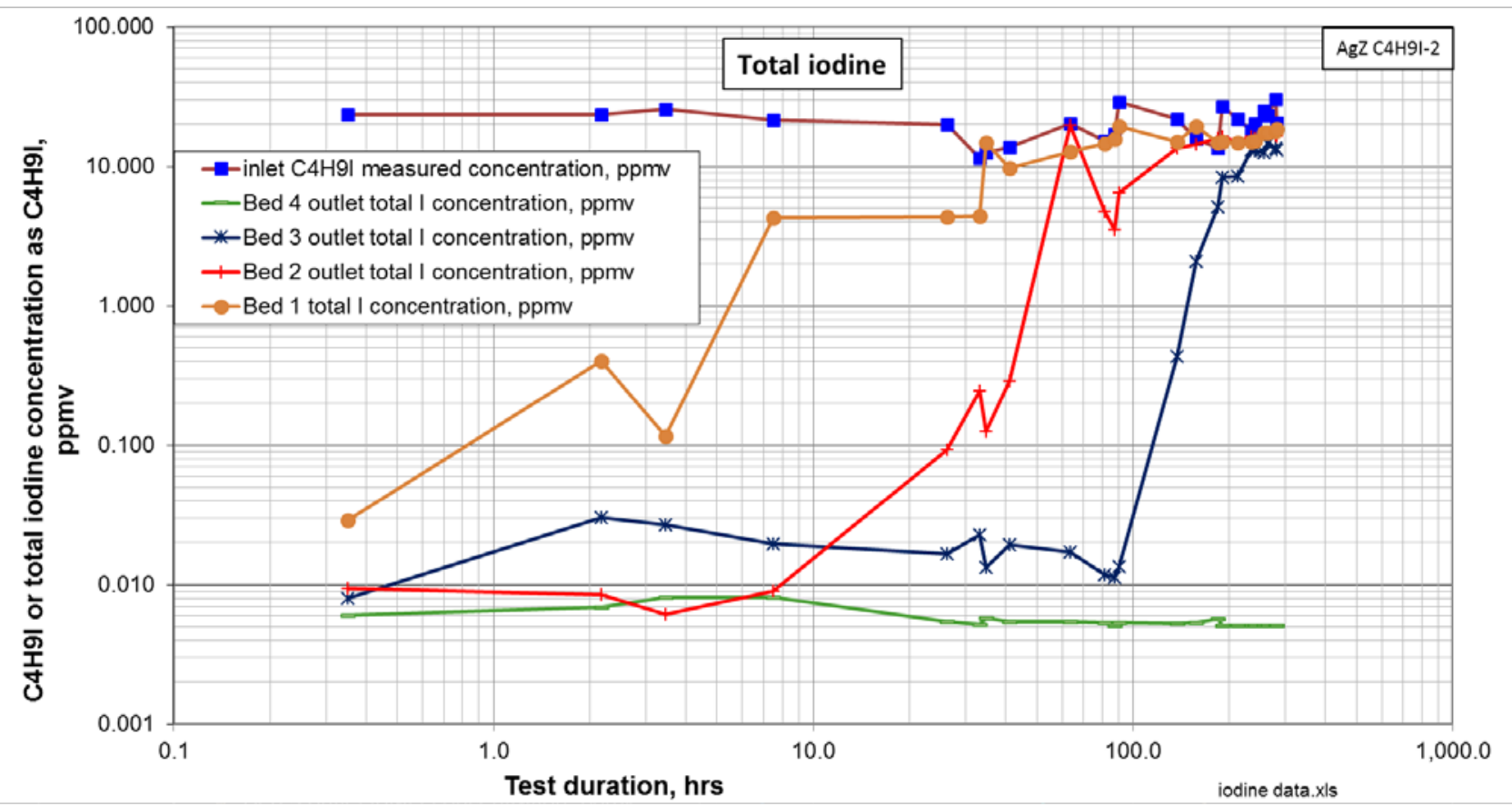

Figure 3-15. Bed segment outlet total iodine concentration trends over time for Test C4H9I-2.

Consistent with data presented in the prior figures, the initial bed outlet total normalized monatomic iodine concentrations (reported as iodobutane) ranged from three to four orders of magnitude less than the inlet iodobutane concentrations, consistent with the initial DFs up to 6,000. Normalized bed outlet total iodobutane concentrations increased until hour 80, when the total Bed 1 outlet iodobutane concentrations reached about 15-20 ppmv for the remainder of the test. Bed 2 outlet total iodobutane concentrations reached $15-20$ ppmv by about hour 200. Bed 3 outlet total iodobutane concentrations also increased to about 15-16 ppmv by the test end. Bed 4 outlet normalized iodobutane concentrations did not increase, because Bed 4 never approached saturation conditions.

While the measured total bed outlet normalized iodobutane concentrations increased to $15-20 \mathrm{ppm}$, this range still did not consistently match the average $20 \mathrm{ppmv}$ iodobutane concentration at the bed inlet. Either some other iodine species, not identified by the GC and not captured in the caustic scrubbers, was formed; or this difference may be attributable to experimental error between the bed inlet and outlet measurements.

\subsection{Sorbent Capacity}

Figure 3-16 shows the post-test adsorbed iodine and silver utilization profiles for the sorbents in these tests. The iodine loading and silver utilization were determined using SEM/EDS measurements of silver and iodine concentrations in the virgin and spent sorbent. As expected, the highest iodine loadings and silver utilizations occurred in Bed 1 of both tests. Since the iodine DFs did not reach unity for either of these tests, even for the 0.5-in. deep Bed 1, these tests may not accurately indicate the maximum saturated capacity for iodine under the test conditions, which would be determined only after impractically long test durations. 


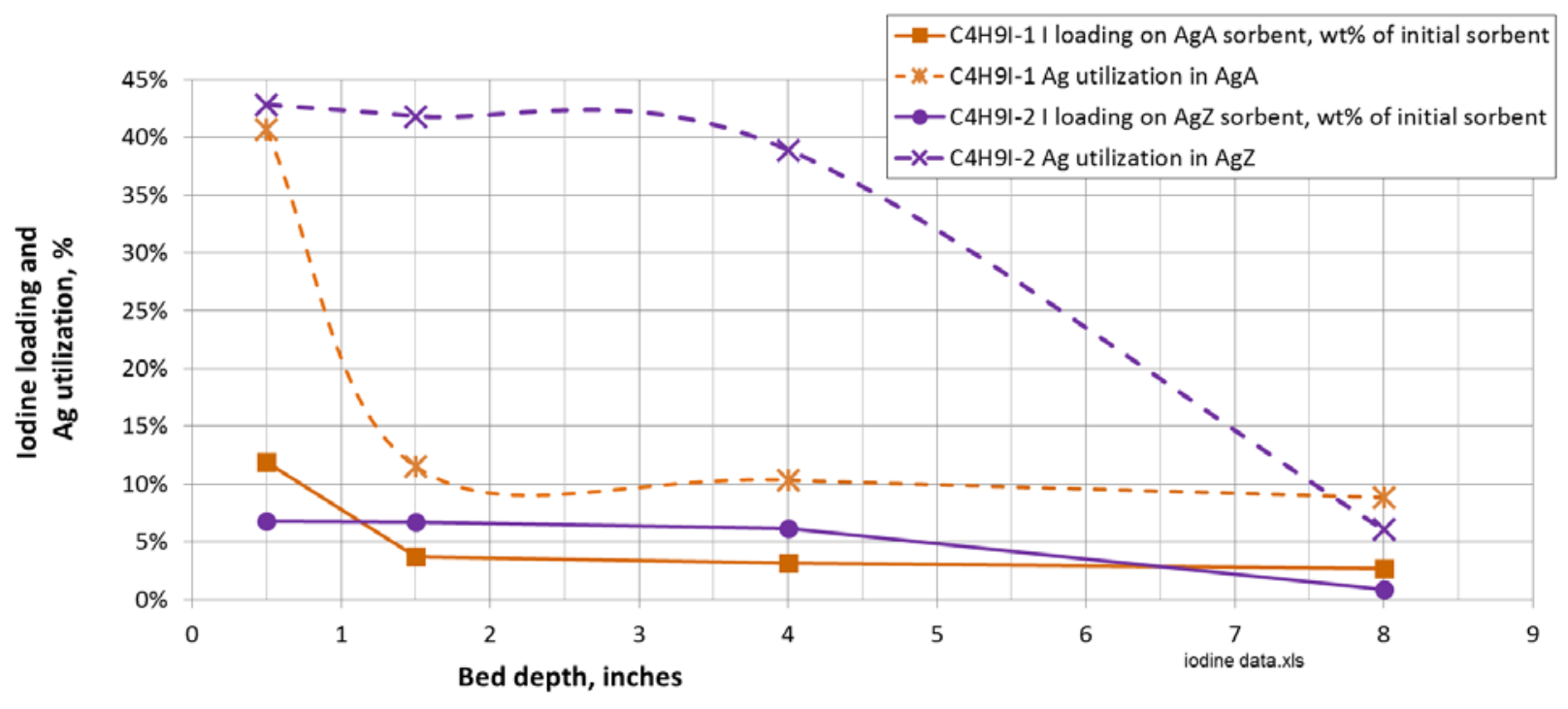

Figure 3-16. Iodine loading and Ag utilization for the iodobutane adsorption tests.

\subsection{Byproduct Species in the Sorbent Bed Outlet Gas}

The GC-FID chromatograms of the bed segment outlet gas for both of these tests showed the ingrowth of many peaks in addition to the iodobutane peak. Peaks detected in the samples of gas from the bed outlets were periodically analyzed by GCMS in attempts to tentatively identify these organic compounds. The GCMS was not as sensitive for these organic compounds as was the GC-FID, so peaks detected on the GC-FID chromatograms were not detected by the GCMS.

An unusual feature of these higher $\mathrm{NO}_{\mathrm{x}}$ tests was that, even after test progression long after DFs were reduced to under 10 , the residual iodobutane in the bed outlet gas remained $\leq 2$ ppmv, under $8-10 \%$ of the inlet iodobutane concentrations. The concentrations of other organic species detected in the GC-FID analysis were not high enough to enable detection and quantification by GCMS. Perhaps the higher $\mathrm{NO}_{\mathrm{x}}$ conditions were too reactive to allow for the formation of appreciable levels of organic byproduct compounds detected in prior, lower- $\mathrm{NO}_{\mathrm{x}}$ tests (Soelberg \& Watson, 2015).

\subsection{Post-Test Purging}

After each test, the sorbent beds were purged to desorb any amounts of iodine that may be loosely held or physisorbed. The purge results for these tests are shown in Figures 3-17 and 3-18. These figures show that only a small fraction of the iodine adsorbed on Bed 1 (about $0.2 \%$ for Test C4H9I-1, and $0.3 \%$ for Test C4H9I-2) desorbed during the approximately 2-day purge periods. In both tests, the amount of iodine desorption significantly decreased after the first 3-4 hours of desorption.

No desorbed iodobutane was detected in these tests; so the amount of iodine desorption from Bed 1 in each test was exclusively iodine that was soluble in $\mathrm{NaOH}$ solution, reported as $\mathrm{I}_{2}$. This result is consistent with other evidence that suggests that the iodine adsorption mechanism, when the gaseous iodine is in the form of organic iodides, occurs when the organic iodide molecule is broken up, and only the iodine adsorbs onto the sorbent. 


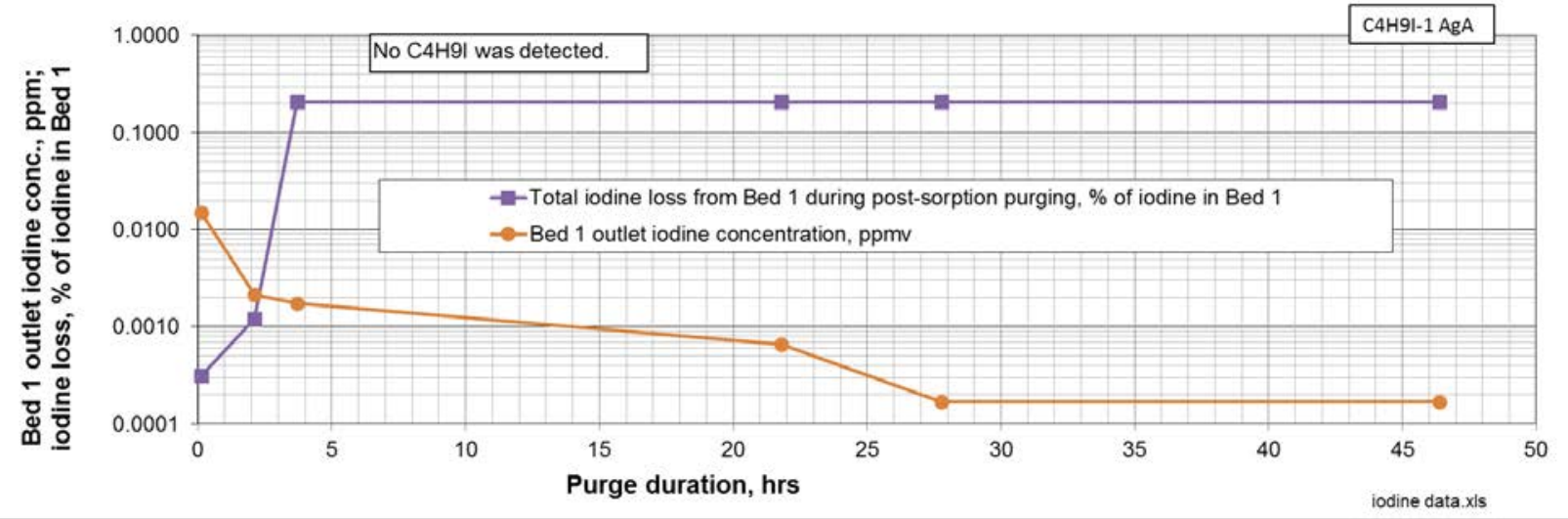

Figure 3-17. C4H9I-1 post-test sorbent purge results.

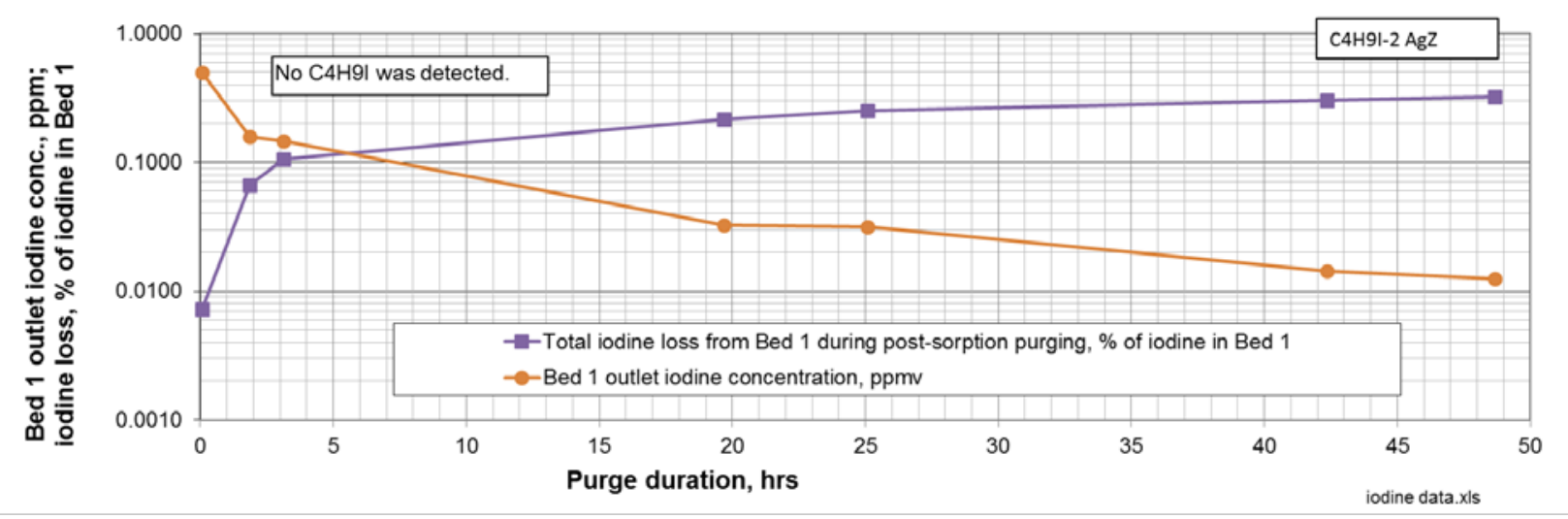

Figure 3-18. C4H9I-2 post-test sorbent purge results.

\section{CONCLUSIONS}

Two deep-bed iodobutane adsorption tests have been performed with higher $\mathrm{NO}_{\mathrm{x}}$ levels, consistent with the recently updated multi-laboratory methyl iodide adsorption test plan (Jubin, Spencer, Soelberg, \& Strachan, 2015). High $(>1,000)$ iodine DFs were achieved with both the silver aerogel and silver zeolite sorbents. The iodine adsorption mass transfer zone for these tests was estimated at 4 inches for both sorbents under the test conditions. Silver utilization for silver aerogel sorbent reached 41\% (up to 12 g adsorbed iodine per $100 \mathrm{~g}$ silver aerogel sorbent), while silver utilization reached $43 \%$ (up to $6.8 \mathrm{~g}$ adsorbed iodine per $100 \mathrm{~g}$ silver zeolite sorbent). These values are generally consistent with results for prior methyl iodide adsorption tests (Soelberg \& Watson, 2015). The results also indicate that, during iodine adsorption process, the organic iodide molecule decomposes so that the iodine can be adsorbed. Even when sorbent breakthrough is reached, the organic iodide molecule continues to decompose; and the unadsorbed iodine that passes through bed is in the form of iodine compounds that are soluble in $\mathrm{NaOH}$ solutions, such as $\mathrm{HI}$ or $\mathrm{I}_{2}$. 


\section{REFERENCES}

Birdwell, J. F. (1991). Iodine and NOx Behavior in the Dissolver Off-Gas and IODCX Systems in the Oak Ridge National Laboratory Integrated Equipment Test Facility. Proceedings of the 21st DOE/NRC Nuclear Air Cleaning Conference, NUREG/CP-011-Vol, pp. 271-298. San Diego, CA.

Determination of Hydrogen Halide and Halogen Emissions from Stationary Sources, Non-Isokinetic Method. (2017, 8 2). 40 CFR 60, Appendix A. US-EPA.

Haefner, D. R., \& Watson, T. (2010). Summary of FY 2010 Iodine Capture Studies at the INL. INL/EXT10018657.

INL. (2015). Gaseous Fission Product Capture Testing. LI-645. Idaho National Laboratory.

Jubin, R. T., Spencer, B. B., Soelberg, N. R., \& Strachan, D. M. (2015). Joint Test Plan to Identify the Gaseous By-Products fo CH3I Loading on AgZ. INL, ORNL. INL/EXT-12-27978, FCRD-SWF2013-000070, ORNL/LTR-2012/604.

Law, J., Soelberg, N., Todd, T., Tripp, J., Pereira, C., Williamson, M., . . Bader, S. (2015). Separation and Waste Form Campaign Full Recycle Case Study. FCRD-SWF-2013-000380, R1.

Method 6020A. (2015, 07). Retrieved from epa.gov: https://www.epa.gov/sites/production/files/201507/documents/epa-6020a.pdf

Nitrogen Tetroxide, N2O4. (n.d.). Retrieved from atomistry.com: http://nitrogen.atomistry.com/nitrogen_tetroxide.html

Soelberg, N., \& Watson, T. (2015). FY-2015 Methyl Iodide Deep-Bed Adsorption Test Report. Idaho National Laboratory. FCRD-MRWFD-2015-000267, INL/EXT-15-36817.

SW-846, "Test Methods for Evaluating Solid Waste, Physical/Chemical Methods". (2015). Retrieved from epa.gov: https://www.epa.gov/sites/production/files/2015-07/documents/epa-6020a.pdf 